RUNNING HEAD: Responses To Social Exclusion In Cultural Context

Responses to Social Exclusion in Cultural Context: Evidence from Farming and

Herding Communities

\author{
Ayse K. Uskul* \\ University of Kent
}

Harriet Over

University of York

In press in the Journal of Personality and Social Psychology

*Corresponding Author:

University of Kent

School of Psychology

Keynes College

Canterbury, CT2 7NP

United Kingdom

Email: a.k.uskul@kent.ac.uk 


\begin{abstract}
In a series of studies, we investigated the role of economic structures (farming vs. herding) and source of ostracism (close other vs. stranger) in social exclusion experiences. We first confirmed that herders rely on strangers to a greater extent than do farmers for economic success (validation study). Next, we verified that farmers and herders understand the concept of ostracism, and its emotional consequences, in similar ways (Study 1). The studies that followed provided converging evidence that cultural group membership shapes sensitivity and responses to social exclusion. Using different methodologies, in Studies 2 and 3, we showed that, whereas the psychological consequences of ostracism by close others are similar for farmers and herders; herders are more strongly affected by ostracism from strangers. The last two studies demonstrated that herders recommend more affiliative responses to ostracism by strangers than do farmers both to those involved in the ostracism event (Study 4) and to naïve individuals (Study 5). Moreover, Study 5 revealed that the amount of time spent with strangers mediated cultural group differences in the extent to which affiliative and aggressive actions are recommended following social exclusion by strangers. Taken together, these results demonstrate that the economic systems on which communities are based shape how their members interact with others and that this, in turn, can shape individuals' responses to social exclusion.
\end{abstract}

Word count: 220

Key words: social exclusion, culture, farmers and herders, belonging, economic activity 
Mahmut makes his living from herding. His livelihood depends on his interactions with strangers. He engages in negotiations with them and closes financial deals to sell the cattle and dairy products that he processes in collaboration with members of his family. Mahmut is motivated to ensure that these people recognize him as a reputable, cooperative, and agreeable person so that he can sell his produce for competitive prices and receive payment as promised. Kahraman makes his living from farming. He relies far less on strangers - he interacts primarily with his immediate and extended family members, neighbors, and other residents of his village, from whom he receives help in harvesting tea. He sells his tea to a major state-owned company, so he does not need to search for a good buyer and engage in negotiations or competition for work-related reasons.

Mahmut and Kahraman pursue economic activities that afford different lifestyles. These different lifestyles, we will argue, have important consequences for their interpersonal relationships. Whereas positive interactions with strangers are very important to Mahmut, they are of little economic consequence to Kahraman. In this paper, we investigate the psychological impact of these relations on individuals' reactions to social exclusion. In particular, we investigate the impact of being ostracized by close others versus strangers for members of farming and herding communities, as well as how individuals from these two groups respond to such ostracism.

\section{Belonging and exclusion}

Group living is essential to human survival. We learn the skills necessary to survive from our group members and cooperate with them in order to deal 
with the physical world (to build shelter, to hunt, to grow crops and so on). Although the structure of human groups is very variable, almost without exception humans live in the company of others. One result of this is that we have a fundamental and pervasive need to belong (Baumeister \& Leary, 1995). That is, we seek to engage in affiliative interactions with those around us and to form long lasting bonds with our group members.

The importance we attach to belonging means that exclusion from the group is very painful for us (Eisenberger, Lieberman, \& Williams, 2003; Williams, 2007). Indeed, being briefly excluded from an online ball game is sufficient to threaten participants' basic psychological needs - reducing their sense of belonging, self-esteem, control and even the extent to which they judge their existence to be meaningful (Williams, Cheung, \& Choi, 2000). Ostracism ${ }^{1}$ is so painful that it hurts even when being excluded is financially beneficial (van Beest \& Williams, 2006) and when participants are told that their exclusion is merely the result of a computer error (Zadro, Wiliams, \& Richardson, 2004). Findings such as these have led some researchers to postulate that we have an evolved mechanism to detect and react against ostracism (Williams, 2007).

It follows that ostracism by those who are critical to our survival ought to be more painful than ostracism by those who are less important to us. Rather surprisingly, however, lab-based studies have not typically found support for this hypothesis. For example, ostracism is painful to us when those who exclude us are members of an outgroup (Smith \& Williams, 2004; Williams, Cheung, \& Choi, 2000), even a despised outgroup (Gonsolkorale \& Williams, 2007). However, a recent diary study focusing on real life social exclusion experiences showed that participants report feeling worse, and experience greater need threat, following 
ostracism by close others such as family members and close friends than following ostracism by acquaintances and strangers (Nezlek, Wesselmann, Wheeler, \& Williams, 2012). This finding is meaningful given the evolutionary importance of close others (e.g., Roberts, \& Dunbar, 2011; Sutcliffe, Dunbar, Binder, \& Arrow, 2012).

Our relationship with those who ostracise us might affect not only our sensitivity to ostracism but also the types of reactions it provokes in us. In their model proposed to account for the diverse range of responses to rejection, Smart Richman and Leary (2009) suggest that if the relationship with the rejecting individual or group is perceived to be of high value, and the cost of the rejection is high, then the rejected individual will be motivated to repair the broken relationship by engaging in affiliative and/or prosocial behaviors. However, if the relationship with the rejecting individual is perceived to be of low value, and the cost of rejection is low, then the rejected individual will be more likely to respond by aggressing or withdrawing.

In this research, we argue that which people matter to individuals' survival is powerfully shaped by affordances of cultural contexts to which those individuals belong. This in turn influences how individuals react and respond to ostracism by different groups. The vast majority of research on social exclusion has been conducted within WEIRD cultures (Western, Educated, Industrialized, Rich and Democratic [Henrich, Heine, \& Norenzayan, 2010], although see Fiske and Yamamoto, 2005, for an exception). Through looking at different cultural groups, we will extend research on ostracism to novel populations and, in doing so, test key theoretical questions about cultural influences on social interdependencies and responses to ostracism. 


\section{Cultural Affordances of Social Interdependence}

Different sets of cultural affordances have been shown to shape people's interdependencies with other individuals and groups (for reviews see Markus \& Hamedani, 2007; Kitayama \& Uskul, 2011). Some of these affordances have been linked to the economic circumstances in a given society. Much of this work has focused on how socio-economic status (e.g., Lachman \& Weaver, 1998; Snibbe \& Markus, 2005; Stephens, Markus, \& Townsend, 2007) and the level of economic development (Greenfield, Maynard, \& Childs, 2003; Inglehart \& Baker, 2000; Loucky, 1976; Kağıtçıbașı \& Ataca, 2005) or material abundance (Adams, Bruckmüller, \& Decker, 2012) within a culture shape social interdependence among its members.

Economic differences between groups can arise not only from variations in the amount of accumulated wealth or patterns of resource distribution, but also from engagement in different types of economic activities that afford different kinds of interpersonal relationships and interdependencies. In this paper, we investigate how the economic structure of different groups influences the nature of social relations within those groups and how this, in turn, influences responses to ostracism. In order to do this, we work with two economic groups: farmers and herders. We adopt a definition of culture that focuses on how psychological processes may be shaped by the sociocultural worlds that people occupy (e.g., Adams, 2005; Adams \& Markus, 2001, 2004; Kroeber \& Kluckhohn, 1952; Markus \& Hamedani, 2007). Using this perspective, we conceptualize economic communities as cultural groups in that they prescribe certain meanings, institutional practices, and ways of being (see also 
Berry, 1979; Berry, van de Koppel, Sénéchal, Annis, Bahuchet, Cavalli-Sforza, \& Witkin, 1986).

Previous research with farming and herding communities has concentrated on how making a living from farming vs. herding influences the level of social interdependence within a culture. Farming typically requires harmonious group collaboration. Moreover, farmers are tied to the land they cultivate and, thus, to fixed communities. In contrast, herding activities do not require much cooperation, but rely on individual decision-making and autonomy. Furthermore, herders are typically not so strongly tied to particular plots of land; their capital can be moved to any location with enough nutrition for their animals.

These characteristics of the lifestyles afforded by the requirements of the economic activity pursued by each group have been suggested to breed interdependence among farmers and independence among herders. Research has indeed shown that farmers tend to show a high degree of social interdependence resulting in stronger emphasis on conformity (Berry, 1967; Barry, Child, \& Bacon, 1959), consultation among members and acting collectivistically (Edgerton, 1965), higher degrees of compliance, conscientiousness, and conservatism in child rearing practices (Barry et al., 1959), and a greater tendency to perceive objects as embedded within their surrounding fields (Berry, 1966; Uskul, Kitayama, \& Nisbett, 2008). Herders, in contrast, tend to show a lesser degree of social interdependence resulting in individualistic social orientations (Edgerton, 1971; Witkin \& Berry, 1975), independent decision-making (Berry, 1967; Barry et al., 1959), individualism and assertiveness in child rearing practices (Barry et al., 1959), and greater 
tendency to perceive objects as separate from their surrounding fields (Berry, 1966; Uskul et al., 2008).

\section{Cultural Differences in Economic Reliance on Strangers}

In the present research, we focus for the first time on another striking difference between farming and herding communities; the extent to which the pursued economic activity requires reliance on strangers (individuals outside of one's immediate social circle). We have chosen to work with tea farmers and herders in the Eastern Black Sea region in Turkey where clear differences exist in the extent to which members of the respective communities have to rely on competition, negotiation, and interaction with individuals they hardly know. ${ }^{2}$

Working in this region allows the implementation of a powerful natural experiment because the farming and herding groups share the same national identity, ethnicity, language, religion and geographic area but differ in the nature of their social relationships shaped by economic demands. These features of the region were exploited in previous research conducted with farmers and herders who were matched on a variety of factors but differed in the type of economic activity pursued for survival, which showed that farmers exhibited a stronger holistic style compared to herders in tasks assessing attention, categorization, and reasoning (Uskul et al., 2008).

In the Eastern Black Sea region of Turkey, tea farming is the most common agricultural practice and it leads to the harvest of three to four crops a year. Production typically takes place in small to medium sized fields owned by families. Reliance on members of the immediate and extended families and on neighbors is common during the harvest seasons. Tea is a consumer staple in 
Turkey; hence the government is heavily involved in the regulation of the tea industry. Although competitive transactions have become more common due to the establishment of private tea companies in recent years, most tea is still purchased and handled by a state-owned company (and some transactions are overseen by local cooperatives rather than by individuals). As a result, farmers in this region tend to be producers only and do not typically engage in competitive, commercial activity with individuals outside of their immediate social circle.

In contrast, herders are both producers and commercialists; they sell cattle and dairy products to factories and commercial enterprises, as well as to local people at weekly markets in neighboring towns. Consequently, they regularly interact with individuals outside of their immediate social circle (who they do not know at all or know only superficially). Given the importance of these interactions for their livelihood, we expected herders to feel motivated to pursue positive relationships with strangers in order to ensure that they are respected, recognized, and valued by them, including after experiencing social problems with them.

In the current research, we thus suggest that living in different economic settings that afford different types of realities would foster different types of interdependencies. For farmers, social interdependencies are likely to be stronger with close others than with distant others, whereas for herders, the boundaries between close and distant others are likely to be less clear-cut. Using Smart Richman and Leary's (2009) terms, given their interdependence with strangers, herders, when compared to farmers, should value relationships with strangers more and perceive the costs of being rejected by them to be higher. 
Given these group differences in the nature of social interdependencies grounded in economic activity, we predicted differences in how members of farming and herding communities would be affected by, and respond to, social exclusion by close others and strangers. We hypothesized differential sensitivity to the source of ostracism such that, in this region, herders would be more negatively affected by ostracism from strangers than would farmers. Moreover, we predicted that herders would be more likely to engage in reparative actions such as endorsing affiliative responses (and less likely to engage in actions that would further harm the relationship such as endorsing aggressive responses) to ostracisers and naïve others following exclusion by strangers. Here, we define strangers in broad terms. Although our predictions are rooted within economic differences between farmers and herders, they are not limited to ostracismrelated responses to strangers on whom individuals rely directly for economic reasons. Rather we expect a generalized tendency in responses to ostracism by all strangers as any stranger might (or not) have the potential to become an economic partner or a customer at any point in the future.

Some support for the hypothesis that strangers matter more in some cultures more than others has been provided by Fiske and Yamamoto (2005) who showed that Japanese participants are less strongly influenced by stranger induced ostracism than are American participants. One interpretation of these results is that relationships with strangers matter less to Japanese people, thus leading them to be less strongly affected by ostracism from them. However, these results are difficult to interpret as the authors did not have a close other comparison condition.

We predicted no differences between herders and farmers' reactions to 
ostracism induced by close others. This prediction is based on previous research highlighting the universal importance of close others (e.g., kin and close friends, see, Roberts, \& Dunbar, 2011; Sutcliffe, et al., 2012) and our own field observations which indicate that members of both communities have very close social ties with members of their families, neighbors and other residents in their village (also see early ethnographic work in the same region by Bellér-Hann \& Hann, 2001; Hann, 1990). Individuals in both groups spend extensive social time with each other in their homes as well as in public places such as coffee houses. Furthermore, they attend community events such as weddings and funerals and support each other during difficult times. We thus predicted that members of both communities would be equally negatively affected by being ostracized by close others and would not differ in the types of responses they endorse in the face of social exclusion by close others.

One outstanding question was whether we would find sex differences in the two cultural groups. Our field observations revealed that the female members of the herding communities tended to be responsible for the production of the diary products such as butter and cheese and other animal products such as animal skin and pelts. Male members, on the other hand, were more likely to engage with strangers for trade purposes. That said, it was not uncommon to see female members of these communities selling diary products at markets and hence interacting with strangers. The division of labor in the farming communities seemed more equal in relation to the main economic activity; both men and women engaged in harvesting the tea, drying it and selling it to the tea companies for further processing. It is thus possible that we would find a gender by culture interaction. However, our field observations also made 
us aware that that attitudes of female members of the herding communities are likely to be shaped by the experiences of the male members of these communities who regularly share their daily experiences (inside and outside of their villages) with members of their families. Based on these observations, we suspect that it may not be only engaging in particular economic activities that produces cultural differences, but also that these economic activities require people to develop different habits, skills and attitudes and these habits, skills and attitudes pervade the culture more generally. This intuition is supported by a recent developmental study conducted within these communities which revealed that young children from the two groups (who do not typically engage in economic activities) differ in their responses to ostracism (Over \& Uskul, 2013). Thus, overall, we did not predict sex differences in the sensitivity and responses to exclusion by strangers in the two communities.

\section{Overview of the Present Research}

We report four studies designed to investigate cultural group similarities and differences in reactions to social exclusion induced by close others versus strangers. Before describing these studies, we report the findings from a validation study in which we aimed to confirm expert views and field observations concerning the number of strangers with whom farmers and herders interact and spend time for work-related purposes. Next we report findings from a study that employed an open-ended interview method to explore understandings of the concept of ostracism among farmers and herders (Study 1). This enabled us to ensure that ostracism was understood similarly among 
the members of these two cultural groups, and that the findings resulting from the remaining studies could not be attributed to a lack of conceptual equivalence.

We examine psychological reactions to ostracism incidents induced by close others or strangers using a reliving task in Study 2 and a vignette approach in Study 3. In Studies 4 and 5, we investigate responses to ostracism by close others or strangers using scenarios depicting incidents of social exclusion by close others versus strangers. Study 4 investigates how individuals from the two communities recommend responding to ostracisers and Study 5 investigates how they recommend responding to new individuals following ostracism by others. $^{3}$

\section{The Field}

The field site for this project consisted of several villages located in the districts of Rize, Erzurum, and Artvin. Artvin, located in northeastern Turkey at the Georgian border, is a northern neighbor of Erzurum. Rize is located on the eastern Black Sea coast, surrounded by the sea in the North and sharply rising mountains in the South. One of the leading sources of income for the inhabitants of the villages in Artvin and Erzurum is animal husbandry, mostly cattle and sheep breeding. Tea farming is the main source of income for the inhabitants of most villages in Rize. Both farming and herding communities in this region are non-nomadic. The region where Rize, Artvin, and Erzurum are located is occupied primarily by ethnic Turks. Islam is the predominant religion. The principal language spoken is Turkish.

The first author and the field coordinator carefully trained interviewers before the start of the project and piloting was conducted on each study to test 
the content and format of the questions. Participants were approached at home, in public spaces (e.g., coffee houses, streets) or on tea or grazing fields during work. The sex of the interviewer and the sex of the participant were always matched. After interviewers introduced themselves and the general goals of the project, they asked individuals for their consent to take part in the study. Individuals who agreed were then introduced the tasks verbally and read out the study questions. ${ }^{4}$ Participants always responded to questions verbally. When answers contained reliving tasks or lengthy descriptions, responses were taperecorded and later transcribed for analysis. When questions contained Likerttype response options, interviewers noted participants' responses on the questionnaire. When participants needed assistance with the use of Likert scales, interviewers provided clarification on the meaning of available response options. Interviewers always clarified any issues raised by participants and checked with them to make sure that the scenarios or questions were correctly understood. Upon completion of each study, participants were given a detailed overview of the goals of the project and handed a small gift for their participation (male participants received a torch and female participants received a small purse). These general methods were pilot-tested in the region and their utility confirmed in prior work (Over \& Uskul, 2013; Uskul et al., 2008).

\section{Participants}

Each reported study employed an independent group of participants. Participants in all studies completed a demographics questionnaire that included questions on age, sex, time spent living in the community, annual income, and most relevant to the present research, the main occupation/source of income. In 
most cases, participants reported spending the majority of their lives in the tested regions. Most participants reported having at least an elementary school degree, with younger people having higher levels of education on average than the elderly. Participants recruited in both communities were comparable to each other in terms of most demographic characteristics; one notable difference emerged in annual income with herders reporting less annual income than did farmers. As in previous work conducted with these groups (see Uskul et al., 2008), income differences did not affect the reported findings in this article. In none of the Studies 1-5 did we find evidence for sex differences in the outcome variables. We therefore do not discuss this variable further after the validation study. Unless noted-otherwise, we tested and confirmed homogeneity of variance for each of the reported ordinary least squares analyses.

\section{Validation Study}

Expert views and our own observations in the field suggested that herders are more likely to interact with strangers (individuals they do not know at all or hardly know) than are farmers. In order to verify this empirically, we asked members of the farming and herding communities to indicate the number of unfamiliar individuals with whom they interact.

\section{Method}

Participants and procedure. Ninety-three farmers ( 46 female; $M_{\text {age }}=$ $39.41, S D=10.69$ ) and 93 herders (47 female; $M_{\text {age }}=38.14, S D=16.28$ ) were approached and asked to respond to three questions concerning their relationships with strangers. All those who were approached responded to all questions. The first question inquired about the number of people with whom 
participants interacted since the beginning of the year whom they had not known before (Q1).5 The second question inquired about the number of people with whom they interacted since the beginning of the year whom they had met before but did not know closely (Q2). We defined interaction as involving being introduced to or having conversations, engaged in trade or negotiation with anyone in a business context. Participants answered both questions by indicating a number in an open-ended response format. If they had difficulty responding to either of these questions, they were encouraged to provide an approximate number. The third question inquired about the amount of time they spent with strangers, by selecting one of the 5 options presented in a Likert-type format $(1=$ I don't spend any time with people I don't know (I hardly know) to $5=$ I spend a lot of time with people I don't know (I hardly know)).

\section{Results and Discussion}

Given that participants were encouraged to give an approximate response to the open-ended questions if they had difficulty identifying a response relying on their memory concerning the number of strangers they had met since the beginning of the year, it is possible that some participants gave extreme or random responses. We therefore first checked for outliers in the data set and ran the analyses after excluding seven participants whose responses fell $3 S D$ s above the mean in either Q1 or Q2 leaving $N=179$.

Since the beginning of the year, participants reported having interacted on average with $7.87(S D=19.14$, range $=0$ to 100$)$ individuals whom they had not met before and $10.44(S D=30.14$, range $=0$ to 200$)$ individuals whom they had met before but did not know closely. The responses to these open-ended questions provided count data with positively skewed distributions (skewness 
statistic for Q1: 3.60 and Q2: 4.81). Although a Poisson regression model is often used to analyze count data, when the variance of the dependent variable is greater than the mean (as was the case here for both questions), a negative binomial regression (NBR) is more appropriate (Coxe, West, \& Aiken, 2009). Thus, we used NBR to analyse the count data associated with each of the openended questions separately, using cultural group and participant sex as independent variables.

The analyses with both questions (see Table 1 for mean frequency counts by cultural group X participant sex) revealed a significant main effect of cultural group, such that, compared to farmers, herders reported having interacted with more individuals that they had not met before, $B=.71, S E=.25, \chi^{2}=7.97, p=.005$ $[95 \% \mathrm{CI}=.22,1.21]$ or did not know closely, $B=.1 .12, S E=.24, \chi^{2}=21.13, p<$ $.001[95 \% \mathrm{CI}=.64,1.60]$. There was also a significant main effect of sex, such that, compared to women, men reported having interacted with more people that they had not known before, $B=.69, S E=.26, \chi^{2}=7.25, p=.007[95 \% \mathrm{CI}=.19$, 1.19], or did not know closely, $B=.84, S E=.25, \chi^{2}=11.25, p=.001[95 \% \mathrm{CI}=.35$, 1.33]. These two main effects were qualified by a cultural group $X$ sex interaction in both questions $\left(\mathrm{Q} 1: B=1.33, S E=.34, \chi^{2}=14.96, p<.001[95 \% \mathrm{CI}=.66,2.00]\right.$; Q2: $\left.B=.91, S E=.33, \chi^{2}=7.44, p=.006[95 \% \mathrm{CI}=.26,1.57]\right)$.

Unfolding these interactions using simple slope analysis (Aiken \& West, 1991) revealed a significant sex difference for herders, with men, compared to women, reporting to have interacted with more people they had not known before (simple slope: $-21.11, t=42.22, p<.001$ ); for farmers this difference was marginally significant (simple slope: $-1.57, t=1.88, p=.061$ ). In response to Q2, there was a significant sex difference within each cultural group in the same 
direction, with a bigger sex difference among herders (simple slope: $-27.38, t=$ 54.76, $p<.001$ ) than farmers (simple slope: $-3.7, t=4.42, p=.02$ ). Furthermore, both male herders and female herders reported having interacted with more people they had not known before or did not know closely than did male farmers and female farmers, respectively (Q1: male herders vs. male farmers: simple slope: $-1.65, t=-1.98, p=.049$, female herders vs. female farmers: simple slope: 17.89, $t=14.54, p<.001, \mathrm{Q} 2:$ male herders vs. male farmers: simple slope: -3.70 , $t=-4.45, p<.001$, female herders vs. female farmers: simple slope: $19.98, t=$ 16.23, $p<.001)$.

Finally, an ANOVA conducted using the entire sample with the question inquiring about the amount of time spent with strangers in general as the dependent variable revealed a similar pattern: herders $(M=2.34, S D=.95)$ reported spending more time with people they did not know or hardly knew than did farmers $(M=2.06, S D=.73), F(1,182)=6.23, p<.05, d=.33$. Consistent with the previous findings, men $(M=2.53, S D=.92)$ reported spending more time with people they did not know or hardly knew than did women $(M=1.88, S D=.66), F(1,182)=31.86, p<.001, d=.81$. Although the cultural group X sex interaction did not reach conventional levels of significance, $F(1,182)=2.36, p=.13$, we still examined sex differences within each cultural group for exploratory purposes. The pattern was similar to the one observed in the open-ended questions; the sex difference was bigger among herders than farmers (herders: $M_{\text {men }}=2.77, S D=.97, M_{\text {women }}=1.93, S D=.77, F(1,182)=$ 25.78, $p<.001, d=.96$; farmers: $M_{\text {men }}=2.30, S D=.85, M_{\text {women }}=1.83, S D=.53, F$ $(1,182)=8.44, p=.004, d=.66)$. 
This study thus provides empirical evidence supporting expert views and our own field observations that members of the herding communities interact with more individuals that they do not know or know very little, and they spend more time with these individuals. The cultural group by sex interaction showed that it was primarily the men in the herding community that reported interacting with strangers. This finding is not surprising given that men tend to take the lead in business interactions.

\section{Study 1}

With no existing work on ostracism within farming and herding communities, we first wanted to ensure that both groups had similar conceptions of ostracism. Thus, to establish conceptual equivalence before proceeding with studies designed to examine differences in reactions to ostracism, we asked members of both farming and herding communities to define ostracism and to describe the emotional consequences of being ostracised.

\section{Method}

Participants and procedure. Fifteen farmers (8 female; $M_{\text {age }}=41.67, S D$ $=11.57$ ) and 15 herders ( 8 female; $M_{\text {age }}=41.93, S D=17.17$ ) were asked to verbally respond to three questions: 1) What do you think 'being ostracized'6 by others' means? 2) In your view, what is the most effective way of ostracizing someone? In other words, if you wanted to ostracize someone, how could you do this best? and 3) How do you think an ostracized person would feel? Participants' responses were tape-recorded and later transcribed for coding.

\section{Results and Discussion}


Question 1: What is ostracism? Participants' responses to this question included a variety of responses focused on the following actions: being left alone, excluded, looked down upon, disliked, belittled, denigrated and not being taken seriously or cared for. With the exception of six participants (three in each cultural group), who gave responses that were irrelevant or too vague to be coded (e.g., ostracism originates from ignorance; ostracism is a bad thing), all participants' responses referenced one or more of the aspects of ostracism listed above. These definitions overlap with definitions of social exclusion cited elsewhere (e.g., Twenge, Baumeister, Tice, \& Stucke, 2001; Williams, 2007) and, importantly, show that both farmers and herders share a similar understanding of what ostracism is.

Question 2: What is the most effective way of ostracizing someone? An initial inspection of participants' responses to this question revealed two major categories: refusal to interact with someone else (e.g., not talking to them, not including them in one's group, ignoring them) and engaging in actions designed to make them look bad (e.g., slandering a person, confronting them with their weaknesses or faults, offending them in some way). ${ }^{7}$ When participants' responses were coded using one of these two categories, Fisher's exact test did not yield significant differences between the groups: The number of participants giving responses that fell in the 'refusal to interact' category $\left(n_{\text {farmers }}=5, n_{\text {herders }}=\right.$ 6) and the 'making someone look bad' category $\left(n_{\text {farmers }}=8, n_{\text {herders }}=4\right)$ did not differ between the two cultural groups, $p=.41$ (two-sided).

Question 3: How do you think an ostracized person would feel? All responses to this question focused on the following emotions or states: being sad, broken, humiliated, bad, a sense of being treated unfairly, or bruised. These 
responses overlap with emotions typically observed in studies designed to examine the emotional consequences of ostracism (for a review see Williams, 2007). With the exception of one participant who failed to provide a relevant response, all participants' responses mentioned one or more of the above emotional consequences, thus yielding no group difference.

We can thus conclude that members of the farming and herding communities understand the concept of ostracism, and the behaviours that are associated with it, in similar ways. Furthermore, members of the two communities predict that ostracism will have similar emotional consequences. These findings provided support for conceptual equivalence which addresses whether the examined concept makes similar sense in the studied groups (Fontaine, 2011) and gave us confidence that we could go on to examine cultural similarities and differences in sensitivity to ostracism and responses to it in these two groups.

\section{Study 2}

In Study 2, we investigated cultural differences in the effects of ostracism by close others and strangers on basic needs and mood. We predicted no cultural group differences in how negatively members of herding and farming communities would be affected following ostracism by close others. However, we predicted that members of herding communities would be more negatively affected by ostracism from strangers compared to members of farming communities. In order to test these predictions, we asked participants to recall and relive an occasion on which they had been ostracised by a close other (or close others) and a stranger (or strangers) and then assessed the effects of these 
experiences on their belonging, self-esteem, perceived control, meaningful existence and mood following the commonly assessed indicators of ostracism related distress (see review by Williams \& Zadro, 2005).

We chose to employ a recall task in this study because a) social exclusion has been shown to be easily relived (Chen, Williams, Fitness, \& Newton, 2008), b) past findings have shown that the exclusion recall task evokes responses comparable to those observed in social rejection experiences created in the lab (see Gardner, Pickett, \& Brewer, 2000; Pickett, Gardner, \& Knowles, 2004), and c) it was more practical given the different ages and diverse educational background of the participants and the constraints on testing (e.g., during a break on a tea field).

\section{Method}

Participants and design. Thirty-five farmers (18 women; $M_{\mathrm{age}}=42.49$, $S D=13.85)$ and 34 herders ( 16 women; $\left.M_{\text {age }}=42.50, S D=17.84\right)$ were recruited to complete a study on social experiences. The study adopted a within-subjects design where all participants completed two recall tasks (close-other induced exclusion, stranger-induced exclusion). The study ended with participants recalling an inclusion event that was not intended for analysis but designed to undo any negative feelings that might have been induced by recalling two social exclusion events.

Procedure. All participants were asked to recall two exclusion events from their own life. In one exclusion task, participants were asked to recall a time when they were excluded by someone they knew well (close other exclusion condition); in the other exclusion task, they were asked to recall a time when they were excluded by someone they did not know well (stranger exclusion 
condition). In each condition, participants were asked to relive the recalled event and describe it orally for a few minutes. Participants' descriptions in each condition were tape-recorded and later transcribed. The order of the two exclusion conditions was counterbalanced (findings did not vary as a function of the order of the exclusion conditions). In a distractor task used between the conditions, participants were asked to orally list as many words as they could think of starting with the letter D. They were given 2-3 minutes to complete this task.

Following each of the reliving tasks, using five-point scales (1: not at all to 5: completely), participants responded to items assessing their psychological reactions at the time of the event including perceived levels of belonging ('I felt rejected', 'I felt like an outsider'), self-esteem ('I felt liked', 'I felt good about myself'), control ('I felt I had control over the course of the interaction, 'I felt powerful'), and meaningful existence ('I felt meaningless', 'I felt non-existent'). They also completed two items assessing mood ('I felt angry', 'I felt sad'). Finally, participants responded to two manipulation check questions designed to assess how close (or distant) the individual involved in the recalled ostracism event was perceived to be ('At the time of this event, how well did you know this individual [these individuals]?' 1: I did not know them at all to 5: I knew them very well and 'At the time of the event, how close were this individual [these individuals] to you?' 1: not close at all to 5: very close).

\section{Results and discussion}

Several participants were excluded from the analyses as a result of failing to recall a time when they were excluded by a close other or a stranger or failing to recall an event that could be clearly classified as social exclusion (e.g., 'My 
daughter failed the university exam'). The number of participants excluded from analyses in each condition did not differ by cultural group (close-other ostracism condition: 15 farmers, 11 herders, $X^{2}(1)<1, n s$; stranger ostracism condition: 14 farmers, 13 herders, $\left.X^{2}(1)<1, n s\right)$.

Manipulation check. The questions forming the manipulation check were highly correlated in both exclusion conditions $\left(r_{\text {close-other }}=.82, p<.001\right.$; $\left.r_{\text {stranger }}=.92, p<.001\right)$ and were therefore averaged to form a closeness index. We entered this closeness index into a repeated-measures ANOVA with exclusion condition (close-other exclusion, stranger exclusion) as a within participants factor and cultural group (farmers vs. herders) as a between participants factor. This analysis revealed a significant main effect of condition, $F(2,26)=62.90, p<$ .001 , demonstrating that individuals recalled in the stranger exclusion event were perceived to be significantly less familiar and less close to participants $(M=$ $2.16, S D=1.29)$ compared to those recalled in the close-other exclusion event $(M$ $=4.50, S D=.88), d=2.12$. The main effect of cultural group, $F(1,26)=1.49, p=$ .23 and the interaction effect between recall task and cultural group, $F(1,26)=$ $1.65, p=.21$, were not significant. Nevertheless, as we had a small sample size and thus low power, we decomposed this nonsignificant interaction effect to confirm that both farmers and herders regarded close others to be 'closer' than strangers. This analysis allowed us to confirm that the manipulation was effective for both samples and to rule out the possibility that herders do not differentiate between close others and strangers. This analysis showed that farmers and herders evaluated the person recalled in the close other exclusion condition equally close $\left(M_{\text {farmers }}=4.50, S D=1.05, M_{\text {herders }}=4.50, S D=.64, n s\right)$, whereas there was a nonsignificant trend for the herders $(M=2.58, S D=1.56)$ to 
perceive the person recalled in the stranger ostracism condition to be more familiar and closer than did farmers $(M=1.84, S D=.98), F(1,26)=2.63, p=.14$. Given this trend, we report the following analysis with and without controlling for this variable.

\section{Self-reported belonging, self-esteem, meaningful existence, and}

mood. Although the majority of participants who failed to recall an appropriate ostracism event overlapped across both recall tasks, some were able to recall being ostracized by a close other, but not by a stranger or vice versa. In order to retain all participants who were able to recall an event in one of the two recall tasks, we ran analyses separately by exclusion condition.

We first created indices for belonging and meaningful existence needs, self-esteem, and $\operatorname{mood}^{8}$ by averaging the two items used to assess each construct (see Table 2 for correlation coefficients for the items used to assess each construct). We then subjected these indices to a MANOVA with cultural group as the independent variable. As predicted, the MANOVA with the threat experienced as a result of close other induced ostracism as the dependent measure did not reveal a significant overall effect of cultural group on the threat indices, $F(4,40)$ $=1.15, p=.35$. Farmers $(M=3.66, S D=.94)$ and herders $(M=3.99, S D=.61)$ reported similar levels of threat experience after recalling ostracism by close others.

Again, as predicted, the MANOVA with the threat experienced as a result of recalling ostracism by a stranger as the dependent measure revealed a significant overall difference between farmers and herders, $F(4,35)=3.04, p=$ .03 , with herders $(M=4.05, S D=.64)$ reporting having experienced significantly higher levels of threat compared to farmers $(M=3.42, S D=.85), d=.84$. In line 
with the overall effect, we also found a significant effect of cultural group on belonging, $F(1,35)=5.29, p=.028$, meaningful existence, $F(1,35)=4.66, p=$ .029 (adjusted for heterogeneity of variance), and negative mood, $F(1,35)=$ $6.78, p=.013$. Self-esteem scores did not vary across the two groups, $F<1$, ns (see Table 2 for descriptive statistics and effect sizes). The overall main effect of culture, $F(4,34)=3.27, p=.024$, and the significant of effect of cultural group on belonging, $F(1,34)=11.05, p=.002$, and $\operatorname{mood}, F(1,34)=4.60, p=.039$, remained unchanged when controlling for how familiar and close the person in the recalled event was perceived to be (i.e., manipulation check question), with the exception of the effect of cultural group on meaningful existence, which became marginally significant, $F(1,34)=2.96, p=.094$.

Although results may to be compromised by low power due to small sample sizes, we followed up the analyses reported above with a mixed ANOVA with exclusion condition (close-other vs. stranger induced ostracism) and type of measure (belonging, self-esteem, meaningful existence, mood) as within participants variables and cultural group (farmers vs. herders) as a between participants variable to examine the hypothesized interaction effect between exclusion condition and cultural group. The interaction between exclusion condition and cultural group failed to reach conventional levels of significance, $F$ $(1,25) 1.49, p=.23$. Nevertheless, we decomposed this interaction effect for exploratory purposes. The simple effect analysis showed that herders were more negatively affected by a stranger induced exclusion event than were farmers, $F$ $(1,25)=7.90, p<.001$, whereas their responses did not vary significantly from each other when the event involved close other induced exclusion, $F(1,25)<1, p$ $=.35$. There was also a trend for farmers to have been affected less negatively by 
a stranger induced ostracism event compared to a close other induced ostracism event, $F(1,25)=2.11, p=.16$, whereas such a trend was not evident in the herder sample, $F(1,25)<1, p=.74$. The three-way interaction between exclusion condition, cultural group and type of measure was not significant, $F$ (3, $75)<1.9$

This study provided initial support for our prediction that farmers and herders would show differential sensitivity to the source of ostracism. Specifically, while farmers and herders did not differ in their psychological reactions to ostracism by close others, herders reported having been affected more negatively by ostracism from strangers than did farmers, experiencing higher belonging and meaningful existence threat and more negative mood.

The conclusions that can be drawn from this study are limited for several reasons. First, the number of participants included in the analyses was small due to some members of the cultural groups having difficulty recalling a relevant ostracism event. Although similar numbers of farmers and herders across both recall tasks failed to recall a relevant ostracism event, the specific reasons for such failure in either group remain unknown. Second, the recall method used in this study leaves open to the possibility that farmers and herders recalled different ostracism experiences that led to different emotional reports. Third, although the interviewers tried to familiarize themselves with the potential participants prior to data collection, having been interviewed by a stranger might have triggered different recall experiences among the members of the two cultural groups that have differential social experiences with individuals with whom they are not closely familiar. Finally, some of the events recalled by participants in this study did not include strangers per se but rather 
acquaintances (as indicated by the manipulation check). To address these limitations, in Study 3 we used a vignette method to test the impact of imagining being ostracised by close others versus strangers on the commonly assessed indicators of ostracism induced stress.

\section{Study 3}

We conducted Study 3 with a goal of replicating the pattern of findings observed in Study 2, using a different method that would allow us to overcome the limitations of the recall method employed. Thus, using a vignette method, we tested the prediction that farmers and herders would not vary in how negatively they would be affected by imagining themselves ostracized by close others, but herders, compared to farmers, would report being more negatively affected when imagining being ostracized by strangers.

\section{Method}

Participants and design. Forty-five farmers (24 women; $M_{\text {age }}=48.71, S D$ $=14.76)$ and 44 herders ( 21 women; $\left.M_{\mathrm{age}}=34.20, S D=13.81\right)$ were recruited to complete a study on social experiences. All participants were read two vignettes, presented in a counterbalanced order, one depicting a situation where they were asked to imagine being socially excluded by a group of people consisting of close others, and another depicting a situation where they were asked to imagine being socially excluded by a group of people consisting of strangers.

Procedure. Participants were asked to vividly visualize the situation described in the vignettes and respond to a series of questions concerning how they would feel if they were to find themselves in the described situation. In both vignettes, we matched the sex of the individuals in the ostracizing group to the 
participant's sex. The close other exclusion vignette used for women read as follows: "Imagine you are waiting at a bus stop on your way to the nearby town. There are other women from your village waiting for the bus. Everyone knows each other well. Other women start chatting among themselves. At the beginning they talk to you as well, but after a while they start excluding you from the conversation. You try to be part of the conversation but no one responds to what you have to say. The bus is delayed so the conversation goes on for some time. During this time, the other villagers continue to leave you out of the conversation." The stranger exclusion vignette read the same except for the second sentence which emphasized that the group consisted of strangers: "These are women from different villages waiting for the bus. No one at the stop knows each other; they are strangers." The two vignettes were presented in a counterbalanced order (the order of the vignettes did not significantly interact with other independent variables). We used the same distractor task as in Study 2 between the two vignettes. Following each vignette, participants responded to the same list of items used in Study 2 to assess perceived levels of belonging, self-esteem, control, meaningful existence, and mood, using the same five-point scale (1: not at all to 5: completely).

\section{Results and discussion}

We first created indices for belonging needs, meaningful existence needs and mood by averaging the two items used to assess each construct as we did in Study 2 (see Table 3 for descriptive statistics and correlation coefficents). ${ }^{10} \mathrm{We}$ then conducted a mixed ANOVA with exclusion condition (close-other vs. stranger induced ostracism) and the three indices (belonging needs, meaningful existence needs, mood) as within participants variables and cultural group 
(farmers vs. herders) as a between participants variable to examine the hypothesized interaction effect between exclusion condition and cultural group. In this study, we controlled for age as farmers were significantly older than herders, $F(1,87)=22.90, p<.001$.

This analysis revealed a significant main effect of exclusion condition, $F$ $(1,86)=6.36, p=.014$, with higher threat reported in the close other exclusion condition $(M=3.47, S D=1.42)$ than in the stranger exclusion condition $(M=$ $2.11, S D=1.00), d=1.11$, and a marginally significant main effect of cultural group, $F(1,86)=3.62, p=.061$, with herders $(M=2.92, S D=.78)$ reporting higher overall threat than did farmers $(M=2.69, S D=.92), d=.27$. Crucially, and as hypothesized, these two main effects were qualified by a significant interaction effect, $F(1,86)=10.58, p=.002, \eta_{p}{ }^{2}=.11$. Unfolding this interaction effect using simple effects analysis revealed that, overall, herders $(M=2.55, S D=$ .93) reported significantly higher threat after imagining themselves being ostracized by a group of strangers than did farmers $(M=1.69, S D=.87), F(1,86)$ $=21.04, p<.001, d=.96$, whereas the two groups reported similar levels of threat after imagining themselves being ostracized by a group of close others $\left(M_{\text {herders }}=3.28, S D=1.42, M_{\text {farmers }}=3.69, S D=1.40, F(1,86)<1, p=.45\right)$. This overall pattern held for each measured construct (all three $p s<.001$ in the stranger induced ostracism vignette and all three $p s>.16$ in the close-other induced ostracism vignette). A comparison across the two exclusion conditions within each cultural group showed that members of both groups reported higher threat when they imagined being ostracized by close others than by strangers (herders: $F(1,86)=7.59, p=.007$, farmers: $F(1,86)=58.98, p<.001)$, however this difference was smaller for herders $(d=.61)$ than for farmers $(d=1.72)$. 
Again, this overall pattern held for each of the three measured constructs, except for meaningful existence need on which herders responded similarly in the close-other and stranger exclusion conditions (see Table 3 for specific comparisons and relevant statistics).

This study revealed findings comparable to those obtained in Study 2 which required participants to recall and relive an ostracism episode that they personally experienced in the past. Specifically, using a vignette method that required participants to imagine themselves being ostracized by a group of close others or strangers, we found additional support for the hypothesis that farmers and herders would show differential sensitivity to the source of ostracism. As predicted, compared to farmers, herders reported that they would be affected more negatively if ostracized by strangers, reporting higher levels of belonging and meaningful existence threat and negative mood, whereas the two groups did not differ in their responses when asked to imagine being ostracized by a group of close others. Both groups reported that they would be more negatively affected by being ostracized by close others than by strangers, however this difference was bigger for farmers than for herders across all three indicators of ostracism-induced stress.

In summary, using a recall method in Study 2 and a vignette method in Study 3, we established that herders show greater sensitivity to being ostracized by strangers than do farmers. If strangers are more important to herders than they are to farmers and have greater impact on their basic needs and mood when ostracized by them, then there should also be differences in responses recommended in the face of ostracism by strangers. In particular, herders should recommend more affiliative responses, which might help them regain approval 
from, and inclusion by, ostracizing strangers. To test this possibility, in Study 4, we examined cultural differences in norms for how to respond to ostracism by close others and strangers.

\section{Study 4}

In this study, we investigated how members of farming and herding communities recommend an individual should respond to ostracism by close others and strangers. To that end, we presented participants with a hypothetical scenario in which an individual was described as being excluded either by a group of close others or a group of strangers and collected their open-ended recommendations for how the ostracised person should react. We then coded these responses as representing affiliation, withdrawal or aggression following the main categories identified in previous work on ostracism (e.g., fight, flight, and tend-and-befriend, see Smart Richman \& Leary, 2009 and Williams, 2007 for reviews; see also MacDonald \& Kingsbury, 2006; Taylor, Klein, Lewis, Gruenewald, Gurung, \& Updegraff, 2000). We predicted that herders would recommend affiliative responses (which would help them repair the broken relationship) to ostracism by strangers more often than would farmers. As in Studies 2 and 3, we predicted no cultural difference in responses recommended for ostracism by close others.

In addition to testing these predictions, we assessed participants' estimates of the impact of these situations on the excluded person. This allowed us to test whether the pattern observed in Studies 2 and 3, which demonstrated that herders were more negatively affected by stranger induced ostracism than were farmers, would replicate when the target person was not oneself (i.e., the 
subject of the recalled experiences as in Study 2 and the imagined target in Study 3) but a hypothetical other.

\section{Method}

Participants and design. Thirty-four farmers ( 17 women; $M_{\mathrm{age}}=45.56$, $S D=10.84)$ and 36 herders ( 18 women; $\left.M_{\mathrm{age}}=44.03, S D=15.05\right)$ were recruited to complete a study on interpersonal relations. All participants were read two scenarios, one depicting a situation where an individual was socially excluded by a group of people consisting of close others, and another depicting a situation where an individual was socially excluded by a group of people consisting of strangers.

Procedure. Participants were asked to vividly visualize the situation described in the scenarios and respond to a series of questions relating to the target person and the event depicted in each scenario. In the scenarios, we matched the sex of the ostracized person and the individuals in the ostracizing group to participants' sex. For male participants, the target person was called Mahmut and the individuals making up the group waiting at the bus stop were described as men. For female participants, the target person was called Selma and the individuals making up the group waiting at the bus stop were described as women. The scenarios used in this study were matched to the vignettes employed in Study 3 as closely as possible.

The close-other induced ostracism scenario read as follows (here we provide as an example the scenario used with women): "A group of women are waiting at the bus stop on their way to the nearby town. These are women from the same village who know each other quite well. One of these women is Selma. Those who are waiting for the bus start chatting among themselves. At the beginning they 
talk to Selma as well, but after a while they start excluding her from the conversation. Selma tries to be part of the conversation but no one responds to what she has to say. The bus is delayed so the conversation goes on for some time. During this time, the other villagers continue leaving Selma out of the conversation." The stranger-induced ostracism condition read the same except for the second sentence which emphasized that the group consisted of strangers: "These are women from different villages who have never met before and are strangers to each other." The two scenarios were presented in a counterbalanced order (findings did not vary as a function of the order of the scenarios). The same distractor task as in Studies 2 and 3 was employed between the two scenarios, which required participants to generate as many words as possible starting with the letter D for 2-3 minutes.

Following each scenario, participants were asked to indicate how they thought the situation would impact Selma, using a 5-point scale (1: very negatively to 5: very positively). Next, using an open-ended format, they were asked to indicate what actions they thought Selma should adopt in response to the situation described in the scenario. Finally, in order to check whether the depicted situations were viewed as equally plausible in both communities, we asked participants to indicate how plausible it would be for the described event to happen to someone in a village in their region (1: not plausible at all to 5: very plausible). ${ }^{11}$

Coding of open-ended responses. Open-ended responses were first coded for whether they indicated a withdrawal, affiliative, or aggressive action. With the exception of seven responses to the close-other ostracism scenario $\left(n_{\text {farmers }}=5, n_{\text {herders }}=2\right)$ and four to the stranger-ostracism scenario $\left(n_{\text {farmers }}=1\right.$, 
$n_{\text {herders }}=3$ ) that were too ambiguous to be coded (e.g., Selma should not feel sad; Selma should choose her friends carefully), all responses were coded to fit one of these three categories. The agreement with a second coder, who was blind to study hypotheses and the conditions of the study, was above $90 \%$ for both the close other and the stranger ostracism scenarios. Disagreements were resolved by discussion.

Withdrawal actions referred to behaviors involving leaving (e.g., she should leave the situation), doing nothing (e.g., she should wait for the bus and do nothing), or ignoring the situation or those involved (e.g., she should not mind them, ignore them). Affiliative actions referred to actions involving adjusting (e.g., she should adjust to the group), being nice to the group (e.g., she should behave in a friendly way towards the group) or correcting or fixing one's own actions (e.g., she should behave differently and think about the situation). Aggressive actions referred to those indicating disagreement with the treatment (e.g., scolding them by saying why on earth they don't speak with her). As shown in Table 4, only a few participants in each group endorsed aggressive responses (perhaps because aggressive actions were perceived to be less socially acceptable in the situations depicted in the scenarios which involved one person being ostracised by a group of other people waiting in the same location). We therefore do not discuss this category further.

\section{Results and discussion}

Plausibility of the event. We first checked how plausible it was that events such as those described in the scenarios would take place in villages in the region where participants resided. An ANOVA with type of scenario (closeother vs. stranger-induced ostracism) as the within participants variable and 
cultural group (farmers vs. herders) as the between participants variable revealed that participants had a slight tendency to view close-other induced ostracism $(M=3.10, S D=1.17)$ as being more plausible than stranger-induced ostracism $(M=2.84, S D=1.29)$. However, this difference did not reach conventional levels of significance, $F(1,67)=2.38, p=.13, d=.21$. There was no significant main effect of cultural group indicating that members of the two groups did not differ from each other in how plausible they thought it would be for a person to experience the incidents described in the scenarios, $F(1,67)<1$, ns. Importantly, type of scenario and cultural group did not interact significantly, $F(1,67)<1, n s$. Thus, both groups perceived the events described in both of the scenarios similarly plausible.

Effects on the target individual. Next, we ran a mixed ANOVA to examine the extent to which participants thought that the target person (Selma/Mahmut) in the scenarios would be impacted by the social exclusion as a function of type of scenario (close-other vs. stranger-induced ostracism, within participants variable) and cultural group (farmers vs. herders, between participants variable). Not surprisingly, in all conditions, participants evaluated the event as having a negative impact on the target person (i.e., all ratings were on the negative end of the scale below the midpoint). There were no significant main effects of cultural group, $F<1$, ns, or type of scenario, $F(1,68)=2.25, p=$ .14 , on these evaluations, but a significant cultural group X scenario interaction effect emerged, $F(1,68)=4.66, p<.05$. Simple effects analysis conducted to unfold this interaction effect showed that while farmers $(M=1.53, S D=.92)$ and herders $(M=1.86, S D=1.20)$ evaluated the impact of the close-other ostracism on the target person similarly, $F(1,68)=1.66, p=.20, d=.31$, they differed in 
their perception of the impact that stranger-induced ostracism would have on the target person. Herders $(M=1.75, S D=.73)$ tended to view this event as having more negative impact on the target person than did farmers $(M=2.15, S D$ $=1.02), F(1,68)=3.54, p=.06, d=.45$. This finding converges with the finding from Studies 2 and 3 demonstrating that herders reported more negative consequences of being ostracized by strangers than did farmers. Thus, compared to farmers, herders perceive stranger induced ostracism as being associated with more negative psychological consequences regardless of whether they or a hypothetical other are the target of exclusion.

Furthermore, a within-groups comparison of the level of impact that the event would have on the target person demonstrated that while farmers evaluated the impact of the stranger-induced ostracism less negatively than the impact induced by close-other ostracism, $F(1,68)=6.51, p=.014, d=.63$; herders did not differentiate between the effects induced by the two kinds of ostracism events, $F(1,68)<1, p=.64$.

Recommendations for action. Finally, we investigated the open-ended responses to the question asking what the target person (Selma/Mahmut) should do in response to the described social exclusion incident. We subjected the frequency of responses that fell in one of the two identified categories (withdrawal vs. affiliation) to a chi-square analysis. The results revealed that in the close-other ostracism condition, farmers and herders endorsed responses in the withdrawal and affiliation categories in similar frequencies (withdrawal: $n_{\text {farmers }}=17, n_{\text {herders }}=15$, affiliation: $\left.\left.n_{\text {farmers }}=10, n_{\text {herders }}=14\right), \chi^{2}(1)<1, n s\right)$. In the stranger-induced ostracism condition, the endorsement of the withdrawal versus affiliative responses varied across farmers and herders, $\chi^{2}(1)$ 
$=3.71, p=.05$. Farmers and herders were equally likely to recommend a withdrawal response, $\chi^{2}(1, N=42)=0.86, p=.35$. Herders, however, were somewhat more likely than farmers to recommend an affiliative response, $\chi^{2}(1$, $N=22$ ) $=2.91, p=.09$. Looking at the data in another way, farmers were more likely to recommend a withdrawal than an affiliative response, $\chi^{2}(1, N=31)=$ 9.32, $p=.002$. Herders were equally likely to recommend a withdrawal or an affiliative response, $\chi^{2}(1, N=33)=0.27, p=.60$.

The relative importance of strangers to herders was thus associated with a greater likelihood of endorsing affiliative responses following ostracism by them. This social norm may allow them to repair their relationship with strangers and thus maintain their important economic connections. Farmers, who are less reliant on relationships with strangers, tend to withdraw from interactions with strangers following ostracism, presumably because they are less invested in the relationship. Importantly, this difference was observed in the absence of a cultural group difference in how plausible social exclusion by close others and strangers were perceived to be.

\section{Study 5}

In Study 4, we demonstrated that herders attempt to repair specific relationships with strangers that have broken down. The vast majority of experimental work on ostracism, however, has focused not on how individuals respond to ostracisers, but on how they respond to new people following an experience of ostracism (for reviews see Williams, 2007; Smart Richman \& Leary, 2009) and has shown that ostracism creates a general threat that influences social interactions beyond the immediate situation. If ostracism by 
strangers really is worse for herders, then this might also influence how they respond to individuals not involved in the original ostracism event. Thus the goal of the final study was to examine farmers' and herders' reactions to a novel person following a social exclusion event induced either by close others or strangers.

Research has shown that, following an experience of ostracism, individuals may seek to reengage with others by conforming, imitating, cooperating, and affiliating with new individuals (e.g., Lakin, Chartrand, \& Arkin, 2008; Maner, DeWall, Baumeister, \& Schaller, 2007; Williams et al., 2000). Such strategies can help individuals reduce the pain experienced as a result of social exclusion and seek a sense of belonging with other people. Research has also shown that not all responses to naïve others following social exclusion events are positive; they may also be of aggressive nature (e.g., Gaertner \& Iuzzini, 2005; Twenge et al., 2001, Twenge, Zhang, Catanese, Dolan-Pascoe, Lyche, \& Baumeister, 2007; Warburton, Williams, \& Cairns, 2006). The situational and individual level factors that might determine whether affiliative or aggressive responses may be adopted remain unclear (see Smart Richman \& Leary, 2009 for a review). In this study, we examined the likelihood with which actions that would help the ostracized person regain social acceptance (via affiliative responses) or actions that would put the ostracized person in confrontation with naïve others (via aggressive responses) are recommended by members of farming and herding communities. In this way, we investigated economic activity and source of ostracism as potential factors that might shape people's responses in the wake of social exclusion. 
To that end, we presented participants with extended versions of the scenarios used in Study 4. In the continuation of the scenario, Selma (Mahmut) was described as encountering a naïve other (a person not involved in the original social exclusion incident) after reaching the market in two different situations. One situation described an encounter with a naïve other, which, due to an accident, caused slight annoyance for the ostracized person and was designed to explore the extent to which affiliative responses would be recommended (we call this the 'innocent incident' from now on). Another situation described an encounter with a naïve other, which involved a rude behaviour on the part of this new person directed to the ostracized person and was designed to explore the extent to which aggressive responses would be recommended (we call this the 'rude incident' from now on). For both situations, we presented participants with forced choice options representing affiliation, withdrawal and aggression. We opted for a forced choice option in this study because we observed that members of both groups were able to spontaneously produce responses in these three categories in Study 3 and with the goal of reducing the number of ambiguous responses and perhaps increasing participants' willingness to recommend aggressive responses.

We hypothesized that, compared to farmers, herders would be more likely to affiliate with, and less likely to aggress against, persons they meet following a social exclusion incident induced by strangers. As before, we predicted no group differences in affiliative or aggressive tendencies against naïve others following a social exclusion incident induced by close others. Finally, we tested whether the amount of time spent with strangers would 
account for cultural group differences in the type of actions recommended by participants.

\section{Method}

Participants and design. Fifty-two farmers (26 women; $M_{\text {age }}=41.13, S D$ $=12.39$ ) and 51 herders ( 26 women; $\left.M_{\mathrm{age}}=39.73, S D=16.61\right)$ were recruited to participate in a study on interpersonal relationships. Participants were randomly assigned to the close-other or stranger-induced ostracism conditions and responded to a question following each of the two incidents.

Procedure. Participants were asked to vividly visualize the situation described in one of the two scenarios used in Study 4 and respond to a couple of questions (described below). As in Study 4, in both scenarios, we matched the sex of the ostracized person and the individuals in the ostracizing group to the participant's sex.

Following the scenario, to highlight the impact the social exclusion experience had on the target person (Selma/Mahmut), participants were read the following additional information (here we provide as an example the scenarios used for female participants): While on the bus and walking towards the market after getting off the bus, Selma kept thinking about how other women at the bus stop left her out of the conversation and ignored her.

To test whether herders would be more likely to recommend affiliative actions when the situation renders a good opportunity to make up for the negative feelings caused by the social exclusion incident by strangers and less likely to recommend aggressive actions when the situation might call for confrontation, participants were read two different situations that took place in the market place and asked to choose a response out of three available options 
that they thought Selma (Mahmut) should adopt in response to the described situation. Response options reflected behaviors that involved an aggressive act, an affiliative act, or an act involving withdrawal. The order of the scenarios was counterbalanced and the order of responses was randomized. The innocent incident and the response options to follow read: "As Selma leaves the market and walks fast to catch her bus, she sees that someone in the market is carrying a box full of chicks. All of a sudden, the cover of the box opens and this person's chicks start running out of the box in all directions. In your view, should Selma ${ }^{12}$

a) help this person pick up his chicks (affiliative) or

b) keep walking in order to catch the bus (withdrawal) or

c) tell the person "they get in my way, why don't you look after your chicks?" (aggressive)

The rude incident and associated response options read: "A stranger is not paying attention to where they are going and bumps into Selma in the market and Selma's shopping bags fall on the floor. Rather than apologizing, the stranger looks annoyed with Selma and looks at her in a rude way. In your view, should Selma

a) tell this person she is angry and that he should watch where he is going (aggressive) or

b) walk away without any further interaction (withdrawal) or

c) kindly says that it is also her fault as she was not paying attention herself (affiliative).

Finally, participants responded to one of the three questions that we examined in the validation study concerning the amount of time spent with individuals that they had not known before or whom they hardly knew $(1=I$ 
don't spend any time with people I don't know [I hardly know] to $5=$ I spend a lot of time with people I don't know [or hardly know]).

\section{Results and Discussion}

We examined the number of participants who chose affiliative, aggressive, or withdrawal responses as actions that the ostracized person should adopt in each of the two situations as a function of cultural background (farmers vs. herders) and the condition (close-other vs. stranger-induced ostracism) using chi-square analyses. We first focused on group differences within each condition, examining whether farmers and herders differed in the types of responses they recommended for each situation. This analysis revealed that, in the innocent incident, while farmers and herders did not differ in their responses in the close other ostracism condition, $X^{2}(2, N=52)=.37, p=.83$, they endorsed a different pattern of responses in the stranger ostracism condition, $X^{2}(2, N=51)=6.06, p$ $=.048$. Specifically, more herders recommended an affiliative response compared to aggressive or withdrawal responses combined than did farmers, $X^{2}$ $(1, N=51)=5.80, p=.016$ (see Table 5 a for frequencies of all responses across conditions and cultural groups).

Next, we focused on the responses within each group as a function of condition. This analysis yielded that, for the innocent incident, farmers differentiated between close other and stranger ostracism conditions, such that a higher number of farmers endorsed the affiliative response compared to aggressive and withdrawal responses combined in the close-other ostracism condition compared to the stranger-induced ostracism condition, $X^{2}(1, N=52)=$ 4.88, $p=.027$. Herders, however did not differentiate between the two conditions; a majority of participants in both conditions endorsed the affiliative 
response compared to the withdrawal and aggressive responses combined, $X^{2}(1$, $N=51)=.07, p=.79$ (see Table 5 a for all frequencies).

A similar pattern was observed for the rude incident. The between group analysis showed that, while farmers and herders did not differ significantly in their responses in the close other ostracism condition, $X^{2}(2)=3.17, p=.21$, the two groups endorsed a different pattern of responses in the stranger ostracism condition, $X^{2}(2)=14.33, p=.001$. Specifically, more farmers endorsed the aggressive response compared to the affiliative and withdrawal responses combined than did herders, $X^{2}(1, N=51)=14.33, p<.001$ (see Table $5 \mathrm{~b}$ for frequencies of all responses across conditions and cultural groups).

The within-group analyses of the responses given for the rude incident also replicated the pattern observed for the innocent incident. Specifically, farmers differentiated significantly between close other and stranger ostracism conditions, such that more farmers recommended aggressive responses compared to affiliative and withdrawal responses combined in the stranger ostracism condition than in the close other ostracism condition, $X^{2}(1, N=52)=$ $5.14, p=.02$. Herders, however, as in the innocent incident, did not differentiate significantly between the close other and stranger-induced ostracism conditions, $X^{2}(1, N=52)=.55, p=.46$ (see Table $5 b$ for all frequencies).

In summary, as predicted, we did not observe cultural group differences in responses when the incidents were encountered following social exclusion by close others. However, group differences emerged for both incidents when they followed social exclusion by strangers. Specifically, compared to farmers, herders recommended more affiliative actions in the face of the innocent incident and fewer aggressive actions in the face of the rude incident. An inspection of within 
group differences revealed while farmers made a stronger distinction between ostracism by strangers and close others than did herders, herders opted for the affiliative and withdrawal actions equally frequently regardless of whether the ostracism was induced by close others or strangers. These findings support the prediction that members of the herding community, who rely more on unknown others for their livelihood and are negatively affected by exclusion from them (as shown in Studies 2 and 3), have a greater motive to undo the pain associated with being excluded by strangers via interacting positively with naïve individuals. These findings, in line with other observations in the social exclusion literature, demonstrate that social exclusion has far reaching consequences going beyond the initial exclusion incident.

Time spent with strangers as a potential mediator. Finally, we tested whether the observed group differences in psychological responses to stranger induced ostracism could be accounted for by the amount of time the members of the two cultural groups spend interacting with individuals they do not know or know very little. To that aim, we first recoded responses into two binary variables with two levels each: affiliative vs. other (i.e., withdrawal and aggressive) in the innocent incident and aggressive vs. other (i.e., withdrawal and affiliative) in the rude incident and ran the regressions to establish the necessary steps before conducting the meditational analyses (Baron \& Kenny, 1986). Replicating the finding observed in the validation study, cultural group (farmers $=0$, herders $=1$ ) significantly predicted the amount of time spent with strangers $(B=1.38, \beta=.51, p<.001)$, with herders reporting spending more time with strangers than farmers. As shown earlier, cultural group also predicted the endorsement of affiliative responses in the innocent incident $\left(B=1.45\right.$, Wald $X^{2}$ 
(1) $=5.51, p=.019)$ and aggressive responses in the rude incident $(B=-2.38$, Wald $\left.X^{2}(1)=12.70, p<.001\right)$. Finally, the amount of time spent with strangers significantly predicted stronger endorsement of affiliative responses in the innocent incident $\left(B=.83\right.$, Wald $\left.X^{2}(1)=8.67, p=.003\right)$ and weaker endorsement of aggressive responses in the rude incident $\left(B=-.81\right.$, Wald $X^{2}(1)=9.10, p=$ $.003)$.

A regression analysis controlling for time spent with strangers showed that cultural group no longer predicted endorsement of affiliative responses in the innocent incident $\left(B=.68\right.$, Wald $\left.X^{2}(1)=.91, p=.34\right)$ and time spent with strangers remained a significant predictor of endorsement of affiliative responses $\left(B=.71\right.$, Wald $\left.X^{2}(1)=5.48, p=.019\right)$, with higher amount of time spent with strangers predicting greater endorsement of affiliative responses. Hayes' (2013) bootstrapping procedure used to test the indirect effect of cultural group on endorsement of affiliative responses through time spent with strangers revealed a bias-corrected and accelerated 95\% confidence interval (95\% BCa CI) of .10 and 2.16 (point estimate $=.53$ ), indicating that time sent with strangers was a significant mediator of the association between cultural group and endorsement of affiliative responses given for the innocent incident because the confident interval did not contain zero.

A second regression analysis controlling for time spent with strangers showed that cultural group remained a significant predictor of endorsement of aggressive responses in the rude incident $\left(B=-1.84\right.$, Wald $\left.X^{2}(1)=6.51, p=.011\right)$ and time spent with strangers remained a marginally significant predictor $(B=-$ .53 , Wald $\left.X^{2}(1)=3.28, p=.070\right)$, with higher amount of time spent with strangers predicting weaker endorsement of aggressive responses. As above, the 
bootstrapping procedure used to test the indirect effect of cultural group on endorsement of aggressive responses through time spent with strangers revealed a bias-corrected and accelerated 95\% confidence interval (95\% BCa CI) of -2.09 and -.05 (point estimate $=-.54$ ), indicating that time spent with strangers was a significant mediator of the association between cultural group and endorsement of aggressive responses given for the rude incident because the confident interval did not contain zero.

The meditational analyses thus showed that the amount of time spent with strangers accounts for the group differences observed in the extent to which affiliative actions are recommended in response to a situation that lacks the potential for confrontation, as well as the extent to which aggressive responses are recommended in response to a situation that has the potential for confrontation. This finding provides evidence for the important role of an external variable afforded by the relevant cultural context in explaining group differences in social relationships.

\section{General Discussion}

The current research investigated how differences in economic activities shape the nature of the social relationships within a community and thus psychological reactions and responses to ostracism. In particular, we tested how farmers and herders respond to ostracism by close others and strangers. We first confirmed that herders rely on strangers to a greater extent than do farmers for economic success (validation study). Next, we verified that farmers and herders understand the concept of ostracism, and its emotional consequences, in similar ways (Study 1). The studies that followed provided converging evidence 
that cultural group membership shapes sensitivity and responses to social exclusion. Using a recall method, in Study 2 and a vignette method in Study 3, we showed that, whereas the psychological consequences of ostracism by close others are similar for farmers and herders; herders are more strongly affected by ostracism from strangers. In two further studies, we showed that herders recommend more affiliative responses to ostracism by strangers than do farmers both to those involved in the ostracism event (Study 4) and to naïve individuals (Study 5). Moreover, Study 5 revealed that the amount of time spent with strangers mediates group differences in the extent to which affiliative and aggressive actions are recommended following social exclusion by strangers, with greater time spent with strangers mediating herders' greater endorsement of affiliative responses in an incident involving an unintended accident and weaker endorsement of aggressive responses in an incident that may call for a conflict.

Recent research has suggested that ostracism by close others is more painful than ostracism by strangers (Nezlek et al., 2012). Here we demonstrate that, although this is true for farmers, not all cultural groups differentiate to the same extent between ostracism by close others and strangers. This, we argue, depends at least in part on the role played by strangers in one's livelihood. Individuals who rely on strangers for economic success respond more negatively to ostracism by them and respond to it with more affiliative behaviours.

More generally, the current research contributes to a small but growing body of evidence suggesting that individual and situational factors moderate responses to social exclusion (e.g., Ayduk, Downey, Testa, Yen, \& Shoda, 1999; Downey, Frietas, Michaelis, \& Khouri, 1998; Zadro, Boland, \& Richardson, 2006; 
see Williams, 2007 for a review). Previous research has suggested that sensitivity to ostracism is an evolved trait that enables detection of social threatening responses and fosters adaptive responses to it (Gonsolkorale \& Williams, 2007). Here we provide systematic evidence that, although ostracism is negatively responded to across communities, the extent of the negative responses it engenders, as well as the types of responses that are deemed appropriate, are culturally variable.

Unlike the majority of research investigating ostracism, our evidence comes from understudied cultural groups. Participants in the present research belong to two economic groups that form the second largest employment sector (agricultural sector) in the world economy (following services sector) and make up about one third of the world's population (Global Employment Trends, 2011). Moreover, the studied region (and the country in which it is located) is nonWestern and is part of a country whose democracy score is far from satisfactory ${ }^{13}$. Our samples are non-industrial, less educated than those typically employed in psychological research, and not rich (either by Turkish and universal standards). Thus the current work adds to the existing database of psychological research that originates primarily from middle-class, White American samples (Arnett, 2008). Our results lead us to caution against focusing exclusively on research conducted with WEIRD populations (Henrich, et al., 2010) and making broad generalisations from very limited samples when constructing evolutionary accounts of ostracism.

\section{Broader Implications and Questions for Future Research}


The current research has implications for relationship models discussed in social and cultural psychology. For example, the current findings are relevant for the patterns of relationships typically seen as normative within individualistic and collectivitistic cultures. Previous research has discussed promotion and maintenance of harmony as a typical characteristic of collectivistic cultures. In the current study, we find that the less collectivistic group (herders: see Uskul et al., 2008) exhibited a greater tendency to suggest avoidance of conflict with those that may be relied upon for economic reasons. Furthermore, our results suggest that defining ingroups and outgroups in less categorical and more functional and relational terms (as proposed by Yuki and colleagues - Yuki, 2003; Brewer \& Yuki, 2007) may be a more suitable approach to understanding social relationships (as least in the cultural contexts examined in this project). Such an approach would be helpful in understanding herders' similar treatment of close others and strangers in a context where individuals relationships can take less voluntary and more inescapable forms of connections (see Adams, Anderson, \& Adonu, 2004), shaped by local economic demands.

The current findings also have relevance for our understanding of the origins of individualism and collectivism. As Triandis (1989) described, one potential root of differences along this dimension are differences in cultural complexity. High cultural complexity may result in being loyal to a large number of ingroups, not just one or two. This pattern of relating to others may result in higher levels of individualism. In the current work, we show that herders rely on and have the motivation to be affiliative to a greater number of individuals than do farmers. This could potentially explain the previously observed cognitive style differences among members of these two communities (see Uskul et al., 2008), 
which demonstrated that herders exhibited lower levels of holistic cognitive style compared to farmers. This group difference was then explained by differences in the degree to which these two communities reinforce either independence of the self from others or interdependence of the self with others due to the nature of the daily economic activities pursued by the members of these two communities. This explanation did not specify which aspect of the economic activities would be responsible for encouraging interdependence over independence or vice versa. The current study suggests that higher levels of commercialism, resulting in greater cultural complexity, which encourages interactions with strangers among herders might be a likely factor leading to lower degree of holistic cognition in this group ${ }^{14}$ (also see Loucky, 1976; Greenfield et al., 2003; Kağıtçıbaşı \& Ataca, 2005). Further research is needed to test this argument.

It is interesting to note that we found a sex difference in the validation study indicating that it was primarily male herders, but not farmers, who reported interacting with a higher number of strangers for work-related reasons. In the main studies, however, we detected no sex differences, as expected. It appears that in the measures included in the current studies assessing psychological responses to ostracism, economic activity played a much more important role than did participants' sex. One possibility, however, is that we failed to observe sex differences due to the relatively small sample sizes. It is worth noting, however, that sex differences have not typically been reported in research on social exclusion even with larger sample sizes (e.g., Williams \& Sommer, 1997). Moreover, in previous work with herders and farmers in the same region, no sex differences were reported in the extent to which holistic or 
analytic cognitive styles were endorsed (Uskul, et al., 2008). At first glance, this might seem counterintuitive because men are more likely than women to engage in the economic activities, especially in the herding communities. We suggest, however, that dominant forms of economic activity endorsed by a community are likely to influence the degree to which the community as a whole interacts with others (and thus be influenced in similar degrees when they get ostracized by them or recommend similar reactions). All members of the community are, therefore, likely to be shaped regardless of whether they directly engage in the economic activities at issue or not (also see Over \& Uskul, 2013). Future research could investigate this claim more directly.

A further point of interest is that we see a generalized pattern of responses to strangers. As predicted, we observed group differences in responses to social exclusion by strangers broadly defined and not to specific strangers defined as economic partners. This may be due to herders' perception of strangers as potential customers or trade partners at some point in the future. Thus, the implications of pursuing a specific type of economic activity can be relatively far-reaching and associated with broad psychological and social relationship patterns. An interesting follow-up question then concerns whether the observed cultural group differences in patterns of relating to strangers following social exclusion extend to other types of interactions with all kinds of strangers. For example, would herders be more likely to help strangers, cooperate and avoid conflict with them to a greater extent? What implications would the currently observed relationship patterns have for psychological phenomena such as intergroup conflict, attitudes towards immigrants and generalized prosocial tendencies? Future research exploring these questions 
could highlight the role of economic activity in broader social and political domains.

One might wonder whether our findings may be unique to the currently studied groups. We do not mean to suggest that the current findings would generalize to all farmers and all herders. Farming and herding communities elsewhere in the world may require different levels of commercialism, competition, and interaction with strangers for economic survival which may lead to different responses to ostracism by strangers. Rather we wish to argue that when a particular group is important to individuals' livelihood within a culture, then ostracism by that group will be more painful and will be responded to in different ways than when that group is less important. Thus, we suspect that findings would generalise to other groups that vary in their interactions with, and reliance on, strangers. Take, for example, individuals that are high in residential mobility or relational mobility. Individuals with high residential mobility (i.e., those moving from one location to another) are likely to have 'dutyfree' friendships and group memberships (as opposed to obligatory friendships and group memberships) (for a review see Oishi, 2010) and those high in relational mobility (i.e., those having greater options in a given society regarding interpersonal relationships and social groups) would have more opportunities to acquire new, maintain current, and leave old relationships and memberships (for a review see Yuki \& Schug, 2012). Individuals with high residential or relational mobility would be expected to interact with strangers because they relocate to new places or because they feel freer to leave old friendships and establish new ones with people they do not know well. Similarly, individuals who have to interact with others unknown to them as part of their work responsibilities 
(residentially or relationally mobile or not) would also be expected to show similar patterns of responses as herders studied in this research. Future research is needed to test the generalizability of the current findings among individuals that show similar characteristics to the economic activity pursued by herders in this research.

A further interesting question for future research concerns whether there would be any cultural differences in immediate responses to ostracism. Previous research has suggested that individuals' immediate responses to ostracism are less susceptible to moderating variables than their more reflective responses (see Williams, 2007, for a review). This point has been supported by recent work with Chinese participants by Ren, Wesselmann, and Williams (in press) who showed that interdependent self-construal facilitated recovery from some of ostracism's negative effects, but did not moderate the initial pain. Culture comparative work is needed to further investigate the potential differences in immediate responses to ostracism and recovery from it in the reflective stage.

Finally, how can we reconcile the current findings with the findings from research on culture and honor that demonstrate herders showing vigilance and acting aggressively in response to threats to their honor (e.g., Cohen \& Nisbett, 1994; Daly \& Wilson, 1988; Nisbett \& Cohen, 1996)? ${ }^{15}$ In line with the literature on culture of honor, the current studies demonstrate that herders take slights by strangers more seriously than do farmers. However, they do not show aggressive responses to these slights; on the contrary they tend to respond in an affiliative manner. Several explanations may underlie this discrepancy. First, members of many honor cultures endorse strong politeness norms because of the potentially severe costs associated with violence erupting out of hostility and anger (see 
Cohen \& Vandello, 2004; Cohen, Vandello, Puente, \& Rantilla, 1999; Cross, Uskul, Gercek-Swing, Alozkan, \& Ataca, 2013). It is possible that herders in the current studies here might have acted out of politeness norms that restricted initial conflict. A second explanation is methodological. It is possible that the scenarios used in the current studies (Studies 3, 4, and 5) did not provide an easy platform for honor-related aggression to erupt (e.g., being excluded (and not insulted) by a group of individuals at a bus stop). Thus the situations employed here are more likely to tap the first category of situations generated by participants in Study 1 in response to the question 'What is the most effective way of ostracizing someone?' that referred to refusals to interact with someone. If the situations were to tap the responses given in the second category of situations generated in Study 1 that referred to engaging in actions to make someone bad such as slandering or offending (see Kerr \& Levine, 2008 who refer to such actions as examples of effective social exclusion strategies), the responses may have taken a different form and resemble more those reported in the culture of honor literature. In fact, this second category of situations show similarities to those generated by Turkish participants in another study as examples of behaviors that could be used to stain others' honor (see Uskul, Cross, Gercek-Swing, Sunbay, \& Ataca, 2012). Further research is needed to explore whether different types of social exclusion acts lead to different psychological responses among farmers and herders for whom strangers matter to a different degree.

\section{Taking a Cultural Approach to the Study of Ostracism}

Although our research questions were based on and inspired by research on social exclusion conducted almost exclusively with members of Western 
societies, our approach was not to treat the studied region as a setting to simply test the replicability of previously observed findings in the literature. Our focus on the sociocultural/economic settings allowed us to generate predictions that were based on the everyday realities of the groups examined in the current research. We also carefully considered and pilot tested the methods that we thought would be meaningful to the members of the studied communities and made sure to that we established conceptual equivalence before conducting our studies designed to investigate responses to social exclusion. Moreover, we used a variety of methods to collect responses (open-ended responses (Studies 1 and 4), self-report on Likert scales (Studies 2 and 3), forced choice (Study 5)) not to have our results be affected by a particular choice of a data collection method and not to systematically subject our findings to problems associated with crosscultural measurement.

Focusing on everyday economic realities of farmers and herders, we were also able to uncover novel evidence that is supportive of the model by Smart Richman and Leary (2009) proposed to understand the factors that determine the kinds of actions individual take in the wake of rejection. Specifically, the current findings suggest that the value of relationship with strangers and the perceived cost of exclusion by them are likely to shape actions of herders whose livelihood depends heavily on their positive interactions with strangers.

Finally, by focusing on the amount of time spent with strangers in Study 5 as a potential mediating factor accounting for group differences observed in the recommended responses to naïve others following an ostracism event, we tested the role played by the everyday realities of farmers and herders in their interpersonal relationships. This approach emphasizes the role of practices 
afforded by economic systems in norms concerning how one should behave in certain situations and helps us bridge the psychological with the external circumstances acknowledging that culture also exists outside of individuals' head (Cohen, 2007; Markus \& Hamedani, 2007).

\section{Concluding Comments}

The present research demonstrates the moderating role of cultural background and source of ostracism in ostracism-related experiences. By working with farming and herding communities in the eastern Black Sea Region of Turkey, we were able to capitalize on the existence of a difference in reliance on distant others for economic reasons while being able to hold constant potentially confounding sociocultural variables such as national identity, language, ethnicity, and religion. Rather than emphasizing internally held variables such as attitudes or values, we focused directly on the everyday realities afforded by sociocultural/economic settings that provide the material basis of psychological outcomes (Markus \& Hamedani, 2007). This way, our work provides evidence on the role of external practices that remain largely unexamined in conventional psychological theory and research and contributes to previous research that has employed cultural-ecological (e.g., Adams, et al., 2012; Berry, 1979; Keller, 2011; Whiting \& Edwards, 1988) or socio-cultural (e.g., Maynard \& Greenfield, 2003; Plaut, Markus, \& Lachmann, 2002; Adams, 2005) approach. In doing so, it helps bridge the psychological with external circumstances (Cohen, 2007; Markus \& Hamedani, 2007) and allows us to situate the ways in which the characters from our introduction, Mahmut and Kahraman, relate to others within their everyday worlds. ${ }^{16}$ 


\section{References}

Adams, G. (2005). The cultural grounding of personal relationship: Enemyship in North American and West African worlds. Journal of Personality and Social Psychology, 88, 948-968. doi: 10.1037/0022-3514.88.6.948

Adams, G., Anderson, S. L. \& Adonu, J. K. (2004). The cultural grounding of closeness and intimacy. In D. Mashek \& A. Aron (Eds.), The handbook of closeness and intimacy (pp. 321-339). Mahwah, NJ: Lawrence Erlbaum Associates.

Adams, G., Bruckmüller, S., \& Decker, S. K. (2012). Self and agency in context: Ecologies of abundance and scarcity. International Perspectives in Psychology: Research, Practice, Consultation, 3, 141-153. doi: $10.1037 / \mathrm{a} 0029348$

Adams, G., \& Markus, H. R. (2001). Culture as patterns: An alternative approach to the problem of reification. Culture \& Psychology, 7, 283-296. doi: $10.1177 / 1354067 X 0173002$

Adams, G., \& Markus, H. R. (2004). Toward a conception of culture suitable for a social psychology of culture. In M. Schaller \& C. S. Crandall (Eds.), The psychological foundations of culture (pp. 335-360). Mahwah, NJ: Erlbaum.

Aiken, L. S., \& West, S. G. (1991). Multiple regression: Testing and interpreting interactions. Newbury Park: Sage.

Arnett, J. (2008). The neglected 95\%: Why American psychology needs to become less American. American Psychologist, 63, 602-614. doi: 10.1037/0003-066X.63.7.602

Ayduk, O., Downey, G., Testa, A., Yen, Y., \& Shoda, Y. (1999). Does rejection elicit hostility in rejection sensitive women? Social Cognition, 17, 245-71. 
doi: 10.1521/soco.1999.17.2.245

Baron, R. M., \& Kenny, D. A. (1986). The moderator-mediator variable distinction in social psychological research - Conceptual, strategic, and statistical considerations. Journal of Personality and Social Psychology, 51, 11731182.

Barry, H., Child, I. L., Bacon, M. K. (1959). Relation of child training to subsistence economy. American Anthropologist, 61, 51-63.

Baumeister, R., \& Leary, M. (1995). The need to belong: Desire for interpersonal attachments as a fundamental human motivation. Psychological Bulletin, $117,497-529$.

Beller-Hann, I., \& Hann, C. (2001). Turkish region: State, market, and social identities on the EAs Black Sea Coast. Oxford: School of American Research Press.

Berry, J. W. (1966). Temne and Eskimo perceptual skills. International Journal of Psychology, 1, 207-229.

Berry, J. W. (1967). Independence and conformity in subsistence-level societies. Journal of Personality and Social Psychology, 7, 415-418.

Berry, J. W. (1979). A cultural ecology of social behaviour. In L. Berkowitz (Ed.), Advances in Experimental Social Psychology. (Vol. 12, pp. 177-206). New York: Academic Press. doi: 10.1016/S0065-2601(08)60262-2

Berry, J. W., van de Koppel, J. M. H., Sénéchal, C., Annis, R. C., Bahuchet, S., Cavalli-Sforza, L. L., \& Witkin, H. A. (1986). On the edge of the forest: Cultural adaptation and cognitive development in Central Africa. Lisse: Swets and Zeitlinger.

Brewer, M. B., \& Yuki, M. (2007). Culture and social identity. In S. Kitayama, \& D. 
Cohen (Eds.), Handbook of cultural psychology (pp. 307-322). New York: Guilford.

Chen, Z., Williams, K. D., Fitness, J., \& Newton, N. C. (2008). When hurt won't heal: Exploring the capacity to relive social pain. Psychological Science, 19, 789795. DOI: $10.1111 / \mathrm{j} .1467-9280.2008 .02158 . x$

Cohen, D. (2007). Methods in cultural psychology. In S. Kitayama \& D. Cohen (Eds.), Handbook of cultural psychology (pp. 196-236). New York: Guilford. Cohen, D., \& Nisbett, R. E. (1994). Self-protection and the culture of honor: Explaining southern homicide. Personality and Social Psychology Bulletin, $20,551-567$.

Cohen, D. \& Vandello, J. (2004). The paradox of politeness. In M. Anderson (Ed.), Cultural shaping of violence: Victimization, escalation, response (pp. 119132). West Lafayette, IN: Purdue University Press.

Cohen, D., Vandello, J., Puente, S., \& Rantilla, A. (1999). "When you call me that, smile!" how norms for politeness, interaction styles, and aggression work together in southern culture. Social Psychology Quarterly, 62, 257-275. doi: $10.2307 / 2695863$

Coxe, S., West, S., \& Aiken, L. (2009). The analysis of count data: A gentle introduction to Poisson regression and its alternatives. Journal of Personality Assessment, 91, 121-136. doi:10.1080/00223890802634175

Cross, S., Uskul, A. K., Gercek-Swing, B., Sunbay, Z., \& Ataca, B. (2013). Confrontation vs. withdrawal: Cultural differences in responses to threats to honor. Group Processes and Intergroup Relations, 16, 345-362.

Daly, M., \& Wilson, M. (1988). Homicide. Hawthorne, NY: Aldine.

Downey, G., Frietas, A. L., Michaelis, B., \& Khouri, H. (1998). The self-fulfilling 
prophecy in close relationships: rejection sensitivity and rejection by romantic partners. Journal of Personality and Social Psychology, 75, 545560.

Edgerton, R. B. (1965). “Cultural” vs. "Ecological” factors in the expression of values, attitudes, and personality characteristics. American Anthropologist, $67,442-447$.

Edgerton, R. B. (1971). The individual in cultural adaptation: A study of four East African societies. Los Angeles: University of California Press.

Eisenberger, N. I., Lieberman, M. D., \& Williams, K. D. (2003). Does rejection hurt? An fMRI study of social exclusion. Science, 302, 290-292. doi:10.1126/science.1089134

Fiske, S. T., \& Yamamoto, M. (2005). Coping with rejection: Core social motives, across cultures. In K. D. Williams, J. P. Forgas, \& W. von Hippel (Eds.), The social outcast: Ostracism, social exclusion, rejection, and bullying (pp. 185198). New York: Psychology Press.

Fontaine, J. R. J. (2011). A fourfold conceptual framework for cultural and crosscultural psychology: relativism, construct universalism, repertoire universalism and absolutism. In F. J. R. van de Vijver, A. Chasiotis, \& S. M. Breugelmans (Eds.), Fundamental Questions in Cross-Cultural Psychology (pp. 165-189). Cambridge: Cambridge University Press.

Gardner, W. L., Pickett, C. L., \& Brewer, M. B. (2000). Social exclusion and selective memory: How the need to belong influences memory for social events. Personality and Social Psychology Bulletin, 26, 486-496.

DOI: $10.1177 / 0146167200266007$

Gaertner, L., \& Iuzzini, J. (2005). Rejection and entitativity: A synergistic model of 
mass violence. In K. D. Williams, J. P. Forgas, \& W. von Hippel (Eds.), The Social outcast: Ostracism, social Exclusion, rejection, and bullying (pp. 307320). New York: Psychology Press.

Global Employment Trends (2011). The challenge of a jobs recovery. International Labour Office. - Geneva: ILO.

Gonsalkorale, K., \& Williams, K. D. (2007). The KKK won't let me play: Ostracism even by a despised outgroup hurts. European Journal of Social Psychology, 37, 1176-1186. doi:10.1002/ejsp.392

Greenfield, P. M., Maynard, A. E., \& Childs, C. P. (2003). Historical change, cultural learning, and cognitive representation in Zinacantec Maya children. Cognitive Development, 18, 455-487. doi:10.1016/j.cogdev.2003.09.004

Hann, C. M. (1990). Tea and the domestication of the Turkish State. SOAS Modern Turkish Studies Programme Occasional Papers 1. Huntingdon: Eothen Press.

Hayes, A. F. (2013). Introduction to mediation, moderation, and conditional process analysis. New York: Guilford Press.

Henrich, J., Heine, S. J., \& Norenzayan, A. (2010). The weirdest people in the world? Behavioral and Brain Sciences, 33, 61-83. doi:10.1017/S0140525X0999152X

Inglehart, R., \& Baker, W. E. (2000). Modernization, cultural change, and the persistence of traditional values. American Sociological Review, 65, 19-51.

Kağıtçıbaşı, Ç., \& Ataca, B. (2005). Value of children and family change: A three decade portrait from Turkey. Applied Psychology: International Review, 54, 317-337.

Keller, H. (2011). Autonomy and relatedness revisited: Cultural manifestations of 
universal human needs. Child Development Perspectives, 6, 12-18. doi:10.1111/j.1750-8606.2011.00208.x

Kerr, N. L., \& Levine, J. L. (2008). The detection of social exclusion: Evolution and beyond. Group Dynamics, 12, 39-52.

Kitayama, S. \& Uskul, A. K. (2011). Culture, mind, and the brain: Current evidence and future directions. Annual Review of Psychology, 62, 419-449. doi: 10.1146/annurev-psych-120709-145357

Kroeber, A. L., \& Kluckhohn, C. K. (1952). Culture: A critical review of concepts and definitions. New York: Random House.

Lachman, M. E., \& Weaver S. L. (1998). The sense of control as a moderator of social class differences in health and well-being. Journal of Personality and Social Psychology, 74, 763-773.

Lakin, J. L., Chartrand, T. L., \& Arkin, R. M. (2008). I am too just like you: Nonconscious mimicry as an automatic behavioral response to social exclusion. Psychological Science, 19, 816-822.

Loucky, J. P. (1976). Psychological consequences of cottage industry: a highland Guatemalan comparison. Anthropology, 8, 115-127.

Maner, J. K., DeWall, C. N., Baumeister, R. F., \& Schaller, M. (2007). Does social exclusion motivate interpersonal reconnection? Resolving the "porcupine problem." Journal of Personality and Social Psychology, 92, 42-55.

DOI: $10.1037 / 0022-3514.92 .1 .42$

Markus, H. R., \& Hamedani, M. G. (2007). Sociocultural psychology: The dynamic interdependence among self systems and social systems. In S. Kitayama \& D. Cohen (Eds.), Handbook of cultural psychology (pp. 3-39). New York: Guilford. 
MacDonald G., \& Kingsbury R. (2006). Does physical pain augment anxious attachment? Journal of Social and Personal Relationships, 23, 291-304.

Maynard, A. E., \& Greenfield, P. M. (2003). Implicit cognitive development in cultural tools and children: Lessons from Mayan Mexico. Cognitive Development, 18, 489-510. doi: 10.1016/j.cogdev.2003.09.005

Nezlek, J. B., Wesselmann, E. D., Wheeler, L., \& Williams, D. (2012). Ostracism in everyday life. Group Dynamics: Theory, Research, and Practice, 91, 91-104. doi: $10.1037 / \mathrm{a} 0028029$

Nisbett, R. E., \& Cohen, D. (1996). Culture of honor. Boulder, CO: Westview Press.

Oishi, S. (2010). The psychology of residential mobility: Implications for the self, social relationships, and well-being. Perspectives on Psychological Science, 5, 5-21. doi: 10.1177/1745691609356781

Over, H., \& Uskul, A. K. (2013). Culture moderates children's responses to ostracism situations. Manuscript submitted for publication.

Pickett, C. L., Gardner, W. L., \& Knowles, M. (2004). Getting a cue: The need to belong and enhanced sensitivity to social cues. Personality and Social Psychology Bulletin, 30, 1095- 1107. doi: 10.1177/0146167203262085

Plaut, V. C., Markus, H. R., \& Lachman, M. E. (2002). Place matters: Consensual features and regional variation in American well-being and self. Journal of Personality and Social Psychology, 83, 160-184.

Ren, D., Wesselmann, E. D., \& Williams, K. D. (in press). Interdependent selfconstrual moderates coping with (but not the initial pain of) ostracism. Asian Journal of Social Psychology.

Roberts, S. \& Dunbar, R. I. M. (2011). The costs of family and friends: an 18- 
month longitudinal study of relationship maintenance and decay. Evolution and Human Behavior, 32, 186-197.

Smart Richman, L. S., \& Leary, M. R. (2009). Reactions to discrimination, stigmatization, ostracism, and other forms of interpersonal rejection: A multimotive model. Psychological Review, 116, 365-383. doi: $10.1037 / \mathrm{a} 0015250$

Smith, A., \& Williams, K. D. (2004). R U There? Effects of ostracism by cell phone messages. Group Dynamics: Theory, Research, and Practice, 8, 291-301.

Snibbe, A. C., \& Markus, H. R. (2005). You can't always get what you want: Educational attainment, agency, and choice. Journal of Personality and Social Psychology, 88, 703-720. doi: 10.1037/0022-3514.88.4.703

Sutcliffe, A., Dunbar, R. I. M., Binder, J. \& Arrow, H. (2012). Relationships and the social brain: integrating psychological and evolutionary perspectives. British Journal of Psychology, 103, 149-168.

Stephens, N. M., Markus, H. R., \& Townsend, S. S. M. (2007). Choice as an act of meaning: The case of social class. Journal of Personality and Social Psychology, 93, 814-830. doi: 10.1037/0022-3514.93.5.814

Taylor, S. E., Klein, L. C., Lewis, B. P., Gruenewald, T. L., Gurung, R. A. R., Updegraff, J. A. (2000). Female responses to stress: tend and befriend, not fight or flight. Psychological Review, 107, 411-429.

Triandis, H. C. (1989). The self and social behavior in different cultural contexts. Psychological Review, 96, 269-289.

Twenge, J. M., Baumeister, R. F., Tice, D. M., \& Stucke, T. S. (2001). If you can't join them, beat them: Effects of social exclusion on aggressive behaviors. Journal of Personality and Social Psychology, 81, 1058-1069. 
doi: 10.1037/0022-3514.81.6.1058

Twenge, J. M., Zhang, L., Catanese, K. R., Dolan-Pascoe, B., Lyche, L. R., \& Baumeister, R. F. (2007). Replenishing connectedness: Reminders of social activity reduce aggression after social exclusion. British Journal of Social Psychology, 46, 205-224. doi: 10.1037/0022-3514.92.1.56

Uskul, A. K., Cross, S., Gercek-Swing, B., Sunbay, Z., \& Ataca, B. (2012). Honor bound: The cultural construction of honor in Turkey and the Northern US. Journal of Cross-Cultural Psychology, 43, 1131-1151. doi: $10.1177 / 0022022111422258$

Uskul, A. K., Kitayama, S. \& Nisbett, R. N. (2008). Ecocultural basis of cognition: Farmers and fishermen are more holistic than herders. Proceedings of the National Academy of Sciences of the USA, 105, 8552-8556. doi: 10.1073/pnas.0803874105

Van Beest, I., \& Williams, K. D. (2006). When inclusion costs and ostracism pays, ostracism still hurts. Journal of Personality and Social Psychology, 91, 918928. doi:10.1037/0022-3514.91.5.918

Yuki, M. (2003). Intergroup comparison versus intragroup relationships: A crosscultural examination of social identity theory in North American and East Asian cultural contexts. Social Psychology Quarterly, 66, 166-183.

Yuki, M. \& Schug, J. (2012). Relational mobility: A socio-ecological approach to personal relationships. In O. Gillath, G. E. Adams, \& A. D. Kunkel (Eds.), Relationship science: Integrating evolutionary, neuroscience, and sociocultural approaches (pp. 137-152). Washington DC: American Psychological Association.

Warburton, W. A., Williams, K. D., \& Cairns, D. R. (2006). When ostracism leads to 
aggression: The moderating effects of control deprivation. Journal of Experimental Social Psychology, 42, 213-220.

Whiting, B. B., \& Edwards, C. P. (1988). Children of different worlds: The formation of social behavior. Cambridge, MA: Harvard University Press.

Williams, K. D. (2007). Ostracism. Annual Review of Psychology, 58, 425-452. doi: 10.1146/annurev.psych.58.110405.085641

Williams, K. D., Cheung, C. K. T., \& Choi, W. (2000). Cyber ostracism: Effects of being ignored over the Internet. Journal of Personality and Social Psychology, 79, 748-762. doi: 10.1037/0022-3514.79.5.748

Williams, K. D., \& Sommer, K. L. (1997). Social ostracism by one's coworkers: Does rejection lead to loafing or compensation? Personality and Social Psychology Bulletin, 23, 693-706. doi: 10.1177/0146167297237003

Williams, K. D., \& Zadro, L. (2005). Ostracism: The indiscriminate early detection system. In K. D. Williams, J. P. Forgas, \& W. von Hippel (Eds.), The social outcast: Ostracism, social exclusion, rejection, and bullying (pp. 19-34). New York: Psychology Press.

Witkin, H. A., \& Berry, J. W. (1975). Psychological differentiation in cross-cultural perspective. Journal of Cross-Cultural Psychology, 1, 5-87.

Zadro, L., Boland, C., \& Richardson, R. (2006). How long does it last? The persistence of the effects of ostracism in the socially anxious. Journal of Experimental Social Psychology, 42, 692-697.

Zadro, L., Williams, K. D., \& Richardson, R. (2004). How low can you go? Ostracism by a computer lowers belonging, control, self-esteem, and meaningful existence. Journal of Experimental Social Psychology, 40, 560567.doi: 10.1016/j.jesp.2003.11.006 


\section{Authors' note}

We thank the British Academy for supporting this research via a small grant (SG090790) and a MidCareer Fellowship (MD130004) awarded to Ayse K. Uskul and the AHRC Culture and the Mind project for giving us the opportunity to discuss the ideas that formed the basis for the current project. We also thank Ebru Tetik for her careful efforts in preparing the studies and organizing the field site, the interviewers who helped with data collection and coding, Roger Mundry and Mario Weick for statistical advice and Susan E. Cross for valuable comments on an earlier draft. Finally, we thank the two anonymous reviewers for making valuable suggestions and our action editor, Lowell Gaertner, for working with us to improve our manuscript. Uskul worked on most of this research while she was at the University of Essex. 


\section{Footnotes}

${ }^{1}$ In this article, we use the terms ostracism and social exclusion interchangeably. 2 The information regarding the two communities summarized below is based primarily on field observations by the first author and expert views gathered from conversations held with officials at the provincial centers overseeing agricultural activities in the region (Rize and Trabzon Gıda, Tarım ve Hayvancılık Ill Müdürlükleri) associated with the Ministry of Food, Agriculture, and Livestock. ${ }^{3}$ We considered all possible paradigms used in the ostracism literature before starting with our studies and opted for the methods employed in the current studies (and using interviewers rather than unassisted data collection) on the basis of their suitability given our following observations in the field. Some locals in the villages where data were collected are illiterate or have very basic levels of literacy. Furthermore in this region Internet connection and hence Web literacy is very limited. Some villages (those who were high up on the mountains) even lacked mobile phone reception. Locals therefore heavily depend on oral and faceto face interactions than any other type of communication. We therefore decided against the cyberball paradigm in our studies on the basis that it would be very difficult to establish face validity. A final reason for deciding against using the cyberball paradigm in these communities was that the use of deception would be very difficult to explain, even with a careful debriefing. We have established trust-based relationships with the members of these communities and we suspected that use of deception might jeopardize these. Furthermore, we were also wary of potential ethical issues that the close other exclusion condition would create as the villagers form very close-knit communities. 
${ }^{4}$ Interviewers attempted to ensure that participants were alone when tested. In most cases this was possible, however in some circumstances the presence of others could not be avoided. Interviewers noted whether the participant was alone or with others at the time of the study. In all studies, analyses were repeated with and without participants who completed the study in the presence of other people. The pattern of findings remained the same in all studies. ${ }^{5}$ Participants for this study were recruited during the same time period, which makes their responses comparable given the time frame introduced in the context of these questions.

${ }^{6}$ We translated ostracism as 'dışlanma' in Turkish.

${ }^{7}$ Responses of seven participants could not be used because they failed to give a relevant answer; most of these participants refused to answer by saying that they would not know how to ostracize someone.

${ }^{8}$ Items assessing control were omitted from the analysis because they did not correlate significantly with each other.

${ }^{9}$ Please note that this analysis included only those participants who successfully recalled a close other and a stranger induced ostracism event and hence is conducted with a smaller sample size $\left(n_{\text {farmers }}=15, n_{\text {herders }}=12\right)$ compared to the MANOVAs reported above. Thus it is likely that some of the differences did not reach conventional levels of significance due to small sample sizes and should be viewed as only suggestive for the pattern of group differences across close other and stranger exclusion conditions.

${ }^{10}$ The items used to measure self-esteem and control did not correlate significantly with each other and hence were not included in the analysis. ${ }^{11}$ Note that this question did not inquire about the frequency with which 
participants thought these social exclusion events would take place.

12 Parenthetical terms were not included in the original versions read to participants.

${ }^{13}$ According to the 2011 democracy scores published by The Democracy Ranking, Turkey scored 66th in 110 countries, with a score of 52.5 out of 100. See http://www.democracyranking.org/downloads/Scores_of_the_Democracy_Rank ing_2011-A4.pdf

${ }^{14}$ We would like to thank Diane Sunar for providing this insight at the regional conference of the International Association for Cross-Cultural Psychology held in Istanbul in 2011.

15 We would like to thank the anonymous reviewer for asking us to elaborate on this point and suggesting potential accounts that might explain this discrepancy. ${ }^{16}$ We would like to thank the two anonymous reviewers for making valuable suggestions and our action editor, Lowell Gaertner, for working with us to improve our manuscript. 
Table 1

Mean Frequency Counts of the Number of Individuals Male and Female Famers and Herders Participants Interacted With Whom They Had Not Known Before (Q1) and Whom They Had Met Before But Did Not Know Closely (Q2)

\begin{tabular}{|l|c|c|c|c|}
\hline & \multicolumn{2}{|c|}{ Farmers } & \multicolumn{2}{c|}{ Herders } \\
\hline & Men & Women & Men & Women \\
\hline Q1 & 8.06 & 1.59 & 35.80 & 7.00 \\
\hline Q2 & 13.43 & 1.78 & 49.00 & 5.47 \\
\hline
\end{tabular}


Table 2

Means (and Standard Deviations) of Outcome Variables as a Function of Recall Task and Cultural Group (Study 2)

\begin{tabular}{|c|c|c|c|c|}
\hline & \multicolumn{4}{|c|}{ Condition } \\
\hline & \multicolumn{2}{|c|}{$\begin{array}{c}\text { Close-Other } \\
\text { Ostracism }\end{array}$} & \multicolumn{2}{|c|}{$\begin{array}{l}\text { Stranger } \\
\text { Ostracism }\end{array}$} \\
\hline & Farmers & Herders & Farmers & Herders \\
\hline Belonging needs & $3.08^{\mathrm{a}}(1.77)$ & $3.87^{a}(.81)$ & $2.74^{\mathrm{b}}(1.33)$ & $3.72^{\mathrm{b}}(1.22)$ \\
\hline Correlation coefficients $(r)$ & $.79 * * *$ & $.59^{* *}$ & $.86^{* * *}$ & $.61^{* * *}$ \\
\hline Meaningful existence needs & $3.08^{\mathrm{c}}(1.55)$ & $3.63^{c}(1.34)$ & $2.86^{\mathrm{d}}(1.57)$ & $3.84^{\mathrm{d}}(1.06)$ \\
\hline Correlation coefficients $(r)$ & $.80^{* * *}$ & $.80^{* * *}$ & $.73^{* * *}$ & $.68^{* * *}$ \\
\hline Self-esteem & $1.53^{\mathrm{e}}(.90)$ & $1.65^{\mathrm{e}}(.91)$ & $1.45^{f}(.89)$ & $1.66^{f}(1.17)$ \\
\hline Correlation coefficients $(r)$ & $.43^{*}$ & $.66^{* * *}$ & $.32^{1}$ & $.56^{* *}$ \\
\hline Mood & $4.00 \mathrm{~g}(.91)$ & $4.11 \mathrm{~g}(1.10)$ & $3.52^{\mathrm{h}}(.98)$ & $4.31^{\mathrm{h}}(.81)$ \\
\hline Correlation coefficients $(r)$ & $.30^{2}$ & $.85^{* * *}$ & $.74^{* * *}$ & $.88^{* * *}$ \\
\hline$\alpha$ for all need satisfaction items & .79 & .90 & .86 & .91 \\
\hline
\end{tabular}

Note: Higher numbers indicate higher threat to belonging and meaningful existence, lower self-esteem, and higher negative mood.

${ }^{\mathrm{a}}(d=.57),{ }^{\mathrm{b}}(d=.77),{ }^{\mathrm{c}}(d=.41),{ }^{\mathrm{d}}(d=.73),{ }^{\mathrm{e}}(d=.13),{ }^{\mathrm{f}}(d=.20), \mathrm{g}(d=.77),{ }^{\mathrm{h}}(d=$ .11)

${ }^{* * *} p<.001,{ }^{* *} p<.01,{ }^{*} p<.05,{ }^{1}(p=.15),{ }^{2}(p=.17)$ 
Table 3

Means (and Standard Deviations) of Outcome Variables as a Function of Type of Ostracism and Cultural Group (Study 3)

\begin{tabular}{|c|c|c|c|c|}
\hline & \multicolumn{4}{|c|}{ Vignette } \\
\hline & \multicolumn{2}{|c|}{$\begin{array}{c}\text { Close-Other } \\
\text { Ostracism }\end{array}$} & \multicolumn{2}{|c|}{$\begin{array}{c}\text { Stranger } \\
\text { Ostracism }\end{array}$} \\
\hline & Farmers & Herders & Farmers & Herders \\
\hline Belonging needs & $3.78^{\mathrm{a}}(1.55)$ & $3.61^{\mathrm{b}}(1.54)$ & $1.70^{c}(1.02)$ & $2.75^{\mathrm{d}}(1.15)$ \\
\hline Correlation coefficients $(r)$ & $.79 * * *$ & $.72^{* * *}$ & $.85^{* * *}$ & $.75^{* * *}$ \\
\hline Meaningful existence needs & $3.27^{\mathrm{e}}(1.65)$ & $2.91^{\mathrm{f}}(1.58)$ & $1.68^{\mathrm{g}}(.95)$ & $2.51^{\mathrm{h}}(1.00)$ \\
\hline Correlation coefficients $(r)$ & $.77^{* * *}$ & $.82^{* * *}$ & $.83^{* * *}$ & $.62^{* * *}$ \\
\hline Mood & $4.02^{\mathrm{i}}(1.39)$ & $3.32^{\mathrm{j}}(1.61)$ & $1.68^{\mathrm{k}}(.85)$ & $2.40^{1}(.91)$ \\
\hline Correlation coefficients $(r)$ & $.76^{* * *}$ & $.69^{* * *}$ & $.75^{* * *}$ & $.42^{* *}$ \\
\hline$\alpha$ for all 6 items & .93 & .92 & .94 & .90 \\
\hline
\end{tabular}

Note: Higher numbers indicate higher threat to belonging and meaningful

existence and higher negative mood, ${ }^{* * *} p<.001,{ }^{* *} p<.01$.

Cultural group comparisons across exclusion conditions:

a vs. c $(F(1,86)=52.52, p<.001, d=1.56)$, b vs.d $(F(1,86)=6.74, p=.01, d=.63)$,

e vs. g $(F(1,86)=27.88, p<.001, d=1.18)$, fvs. h $(F(1,86)=2.19, p=.14, d=.30)$,

${ }^{\text {i vs. } \mathrm{k}}(F(1,86)=70.96, p<.001, d=2.47),{ }^{\text {j vs. }}{ }^{l}(F(1,86)=12.04, p=.001, d=.72)$

Cultural group comparisons within each exclusion condition:

a vs. b $(F(1,86)<1, p=.83, d=.011)$, c vs.d $(F(1,86)=26.19, p<.001, d=.97)$,

e vs. f $(F(1,86)<1, p=.65, d=.22)$, ${ }^{\text {gvs. h }}(F(1,86)=16.06, p<.001, d=.85)$,

vs. $\mathrm{j}(F(1,86)=1.99, p=.16, d=.24),{ }^{\mathrm{kvs.}} \mathrm{l}(F(1,86)=16.09, p=.001, d=.82)$ 
Table 4

Distribution of Action Recommendations Per Type of Scenario and Cultural Group (Study 4)

\begin{tabular}{|l|c|c|c|c|}
\hline & \multicolumn{3}{|c|}{ Type of Scenario } \\
\hline & \multicolumn{2}{|c|}{$\begin{array}{c}\text { Close-other } \\
\text { Ostracism }\end{array}$} & $\begin{array}{c}\text { Stranger } \\
\text { Ostracism }\end{array}$ \\
\hline \multicolumn{1}{|c|}{ Recommended Action } & Farmers & Herders & Farmers & Herders \\
\hline Withdrawal responses & 17 & 15 & 24 & 18 \\
\hline Affiliative responses & 10 & 14 & 7 & 15 \\
\hline Aggressive responses & 2 & 3 & 2 & 0 \\
\hline
\end{tabular}


Table 5a

Distribution of Action Recommendations Per Type of Scenario and Cultural Group (Study 5, Innocent Incident)

\begin{tabular}{|l|c|c|c|c|c|c|}
\hline & \multicolumn{3}{|c|}{ Farmers } & \multicolumn{3}{c|}{ Herders } \\
\hline & \multicolumn{2}{|c|}{ Recommended Response } & \multicolumn{2}{c|}{ Recommended Response } \\
\hline Condition & affiliative & withdrawal & aggressive & affiliative & withdrawal & aggressive \\
\hline $\begin{array}{l}\text { Close-other } \\
\text { ostracism }\end{array}$ & 20 & 5 & 2 & 20 & 4 & 1 \\
\hline $\begin{array}{l}\text { Stranger } \\
\text { ostracism }\end{array}$ & 11 & 10 & 4 & 20 & 5 & 1 \\
\hline
\end{tabular}

Table 5b

Distribution of Action Recommendations Per Type of Scenario and Cultural Group (Study 5, Rude Incident)

\begin{tabular}{|l|c|c|c|c|c|c|}
\hline & \multicolumn{3}{|c|}{ Farmers } & \multicolumn{3}{c|}{ Herders } \\
\hline & \multicolumn{2}{|c|}{ Recommended Response } & \multicolumn{2}{c|}{ Recommended Response } \\
\hline Condition & affiliative & withdrawal & aggressive & affiliative & withdrawal & aggressive \\
\hline $\begin{array}{l}\text { Close-other } \\
\text { ostracism }\end{array}$ & 12 & 4 & 11 & 9 & 9 & 7 \\
\hline $\begin{array}{l}\text { Stranger } \\
\text { ostracism }\end{array}$ & 3 & 4 & 18 & 9 & 12 & 5 \\
\hline
\end{tabular}

